\title{
Psychological Trauma and Resilience of Police Officers Involved in an Ambush: An Exploratory Study
}

\author{
Erin A. Teaff \\ West Virginia University, eteaff@mix.wvu.edu
}

Follow this and additional works at: https://researchrepository.wvu.edu/etd

Part of the Counseling Psychology Commons

\section{Recommended Citation}

Teaff, Erin A., "Psychological Trauma and Resilience of Police Officers Involved in an Ambush: An Exploratory Study" (2019). Graduate Theses, Dissertations, and Problem Reports. 7438.

https://researchrepository.wvu.edu/etd/7438

This Dissertation is protected by copyright and/or related rights. It has been brought to you by the The Research Repository @ WVU with permission from the rights-holder(s). You are free to use this Dissertation in any way that is permitted by the copyright and related rights legislation that applies to your use. For other uses you must obtain permission from the rights-holder(s) directly, unless additional rights are indicated by a Creative Commons license in the record and/ or on the work itself. This Dissertation has been accepted for inclusion in WVU Graduate Theses, Dissertations, and Problem Reports collection by an authorized administrator of The Research Repository @ WVU.

For more information, please contact researchrepository@mail.wvu.edu. 
Psychological Trauma and Resilience of Police Officers Involved in an Ambush: An Exploratory Study

Erin A. Teaff, M.S.

\begin{abstract}
Dissertation submitted to the College of Education and Human Services at West Virginia University in partial fulfillment of the requirements for the degree of
\end{abstract}

Doctor of Philosophy
in
Counseling Psychology

Jeffrey Daniels, Ph.D., Chair Samuel Berhanu, Ph.D. Monica Leppma, Ph.D. Christine Schimmel, Ed.D.

Department of Counseling, Rehabilitation Counseling, and Counseling Psychology

Morgantown, West Virginia 2019

Keywords: trauma, resilience, police officers, ambush, counseling Copyright 2019 - Erin A. Teaff 


\begin{abstract}
Psychological Trauma and Resilience of Police Officers Involved in an Ambush: An

Exploratory Study
\end{abstract}

\title{
Erin A. Teaff
}

Law enforcement officers are widely recognized as having one of the most dangerous and stressful occupations, which can lead to lasting physical and psychological impacts. While research has examined the psychological trauma and resilience experienced by police officers, there have been very few research studies involving ambushes. Due to the continued risk of ambushes on police officers, gaining insight into the trauma and resilience of officers during these types of situations would be beneficial in providing psychologists with information to aid in their treatment officers involved in an ambush and similar unprovoked attacks. The primary aim of this study was to examine the differences in symptomatology of trauma and level of resilience among victim and witness police officers involved in an ambush. In the spring of 2019, police officers ( $n=19$ ), including 15 victim officers and 4 witness officers, completed self-report questionnaires. Results from this exploratory study demonstrated that years of experience as an officer was significantly correlated with age at the time of the ambush. An independent samples $t$-test showed there were no statistically significant differences between victim officers and witness officers on measures of trauma symptomatology and level of resilience. Additionally, it showed there were no statistically significant differences between officers who received counseling and those who did not receive counseling after an ambush, on measures of trauma symptomatology and level of resilience. 


\section{Acknowledgements}

First, I would like to thank Dr. Daniels for your encouragement and support throughout my time in this program. Learning from you has truly been a pleasure. I would also like to thank Dr. Bartee for all that you have taught me during the program and your support these past several years. To Dr. Leppma, Dr. Schimmel, and Dr. Berhanu, thank you for your time, energy, expertise, and support throughout the course of this project. To Mom, Dad, Jamie, Jesse, Rudy, and Grey, thank you for your constant encouragement, love, and dedication to helping me pursue my goals. None of this would have been possible without you. To Christopher, you have brought so much happiness and love into my life. The support and encouragement you have given me has helped in so many ways. I love you. 


\section{Table of Contents}

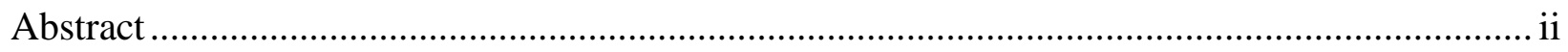

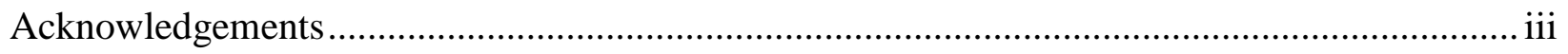

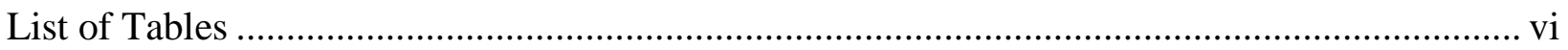

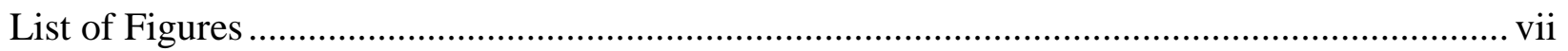

Chapter 1: Introduction and Literature Review ............................................................ 1

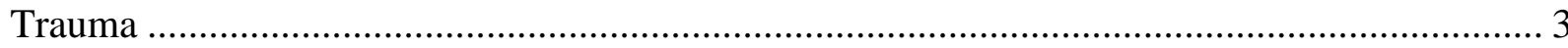

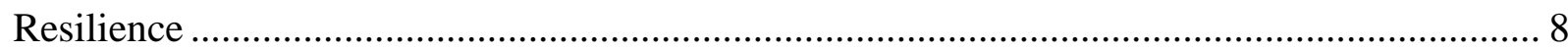

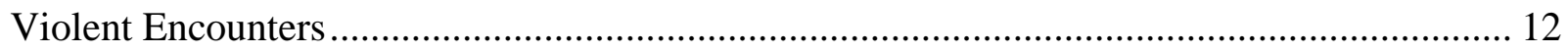

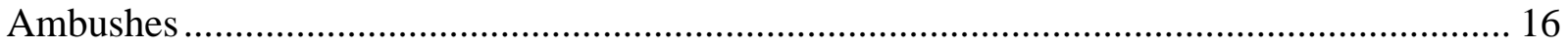

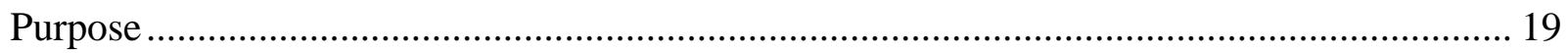

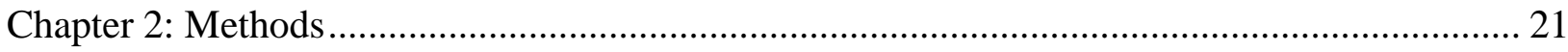

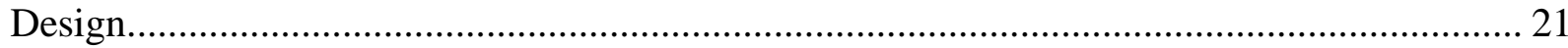

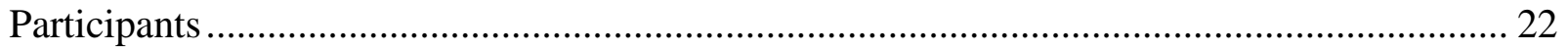

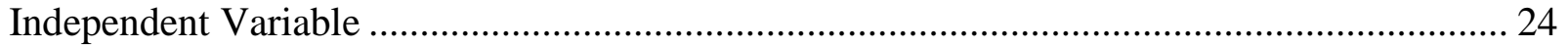

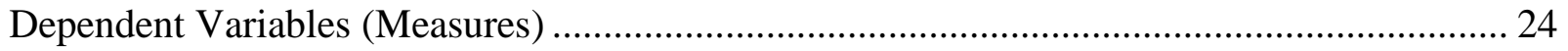

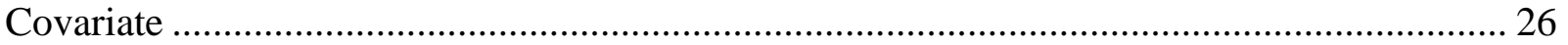

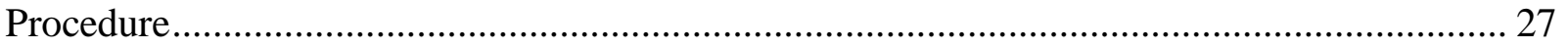

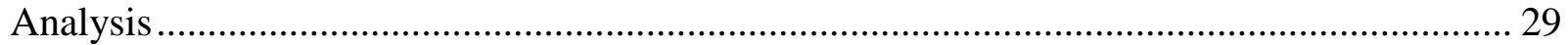

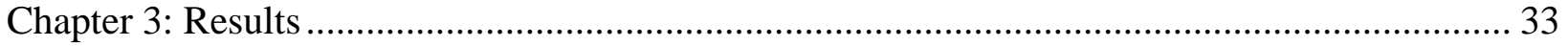

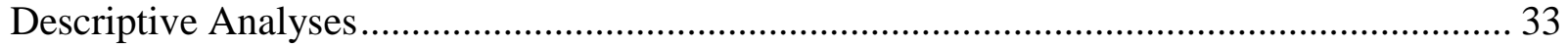

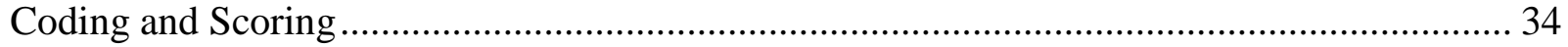

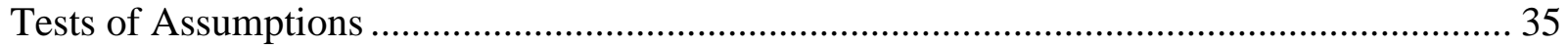

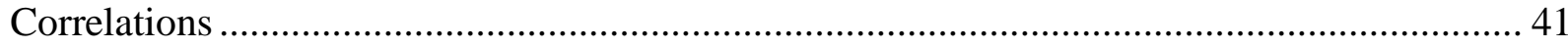

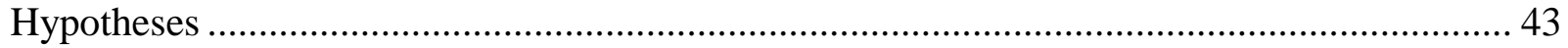

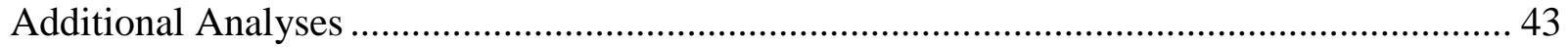

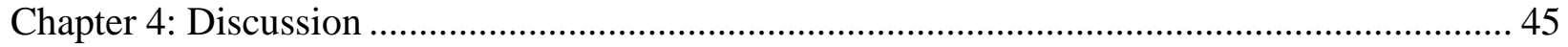

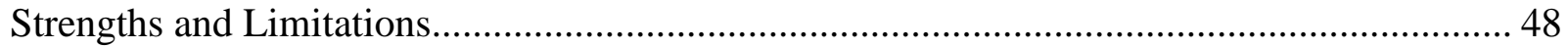

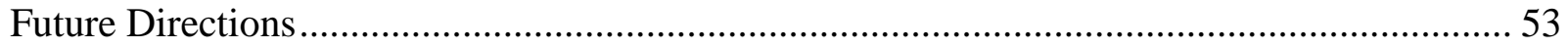

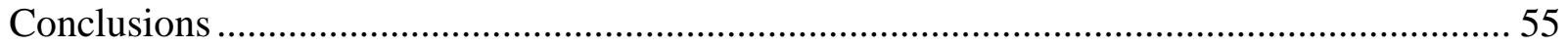

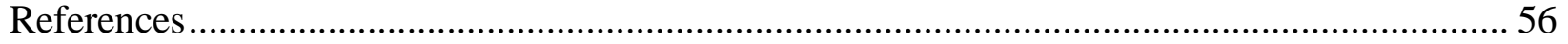

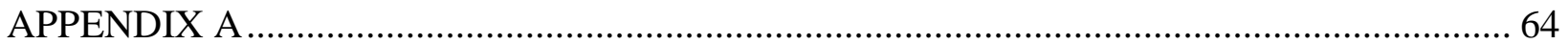




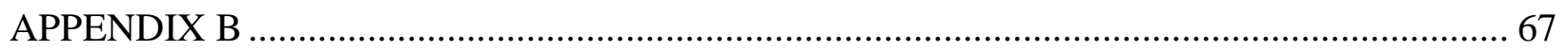

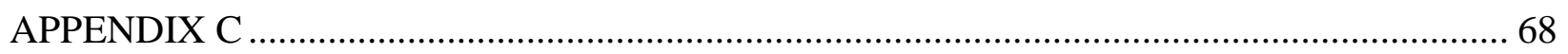

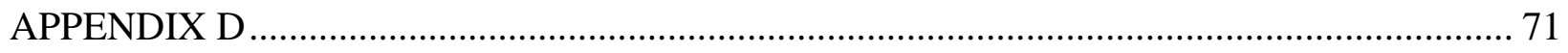

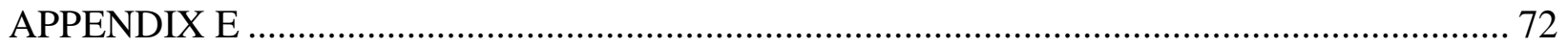

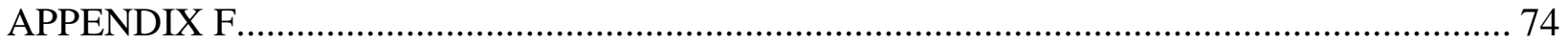

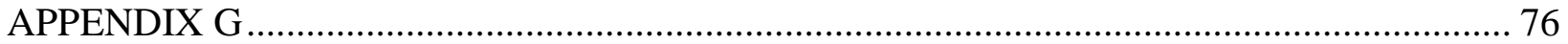

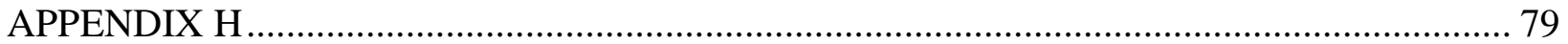

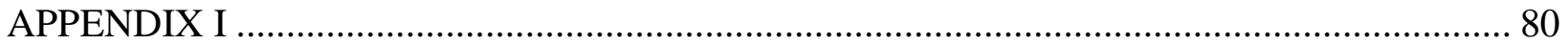

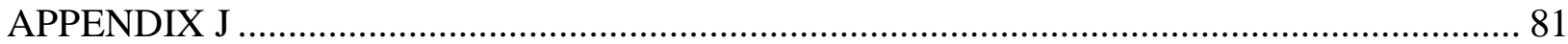

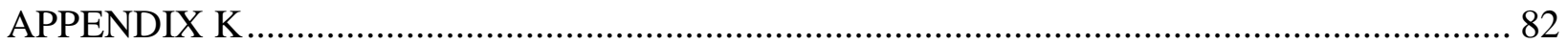

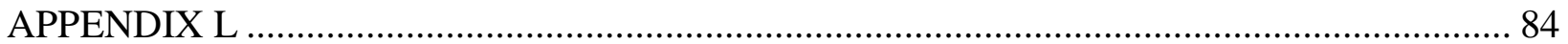


List of Tables

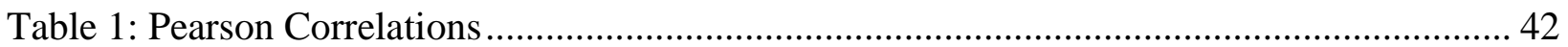




\section{List of Figures}

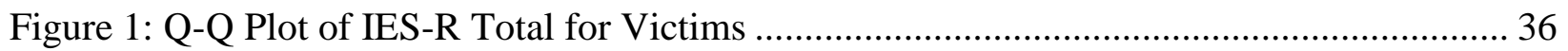

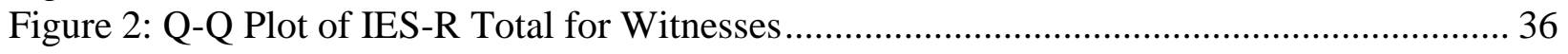

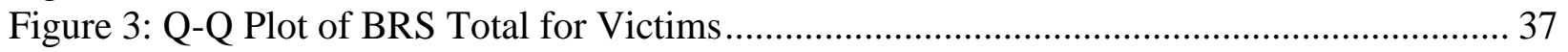

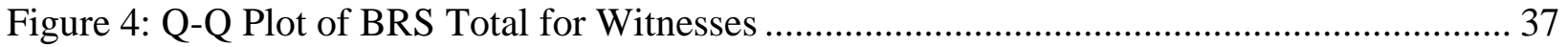

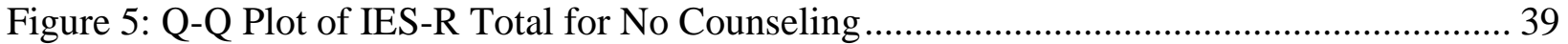

Figure 6: Q-Q Plot of IES-R Total for Counseling ................................................................ 39

Figure 7: Q-Q Plot of BRS Total for No Counseling ........................................................... 40

Figure 8: Q-Q Plot of BRS Total for Counseling ............................................................... 40 


\section{Chapter 1: Introduction and Literature Review}

Law enforcement officers are widely recognized as having one of the most dangerous and stressful occupations (McCaslin et al., 2006). Officers are often exposed to life-threatening situations such as disturbance calls, arrest situations, investigating suspicious persons or circumstances, traffic pursuits and stops, and ambushes (Crosby \& Lyons, 2016; McCaslin et al., 2006; Young, 1990). Ambush-related attacks have continuously been a threat to police officers in the United States. According to Daniels, Sheets, Wright, and McAllister (2019), "The Federal Bureau of Investigation's Uniform Crime Report (UCR) defines an ambush against a law enforcement officer (LEO) as 'Assigned or on-view activities where the officer is assaulted, unexpectedly as the result of premeditated design by the perpetrator(s)."' (p. 4). Ambushes are further broken down into two categories: (1) ambushes that include entrapment and premeditation and (2) ambushes that include a spontaneous or unprovoked attack. During the 18year period from 1970 to 1987,170 law enforcement officers were killed by ambush in the United States (Young, 1990). During this time, these deaths represented 9.5 percent of all national police homicides, and averages 9.4 deaths per year. More recently, during the 15 -year period from 2000 to 2014, ambush attacks claimed the lives of 144 officers nationally, averaging approximately 9.6 deaths per year (International Association of Chiefs of Police [IACP], 2014). Additionally, the survival rate for an ambush attack is approximately 46 percent (International Association of Chiefs of Police [IACP], 2014).

Although people tend to emphasize the physical danger associated with the work of police officers, the psychological danger of this work tends to be overlooked (Violanti, 2006). 
Police officers are often exposed to multiple traumatic experiences during their career, putting them at an increased risk for developing psychological disorders. These types of traumatic experiences can also affect an officer's physical health (Andersen \& Papazoglou, 2016; Hartley, Sarkisian, Violanti, Andrew, \& Burchfiel, 2013). Regardless of the nature of the traumatic event, there are many factors that must be considered. A prevalent result of experiencing a traumatic event is posttraumatic stress disorder (PTSD). Symptoms and severity vary widely based on the individual. Reactions to events and degree of recovery also vary significantly based on prior risk factors. Risk factors can be categorized as pretraumatic, peritraumatic, and posttraumatic (American Psychiatric Association, 2013).

Police officers are subject to stressful events on a daily basis, with multiple exposures in a single day being common. It is vital that symptoms of stress-related disorders are recognized early so that interventions can take place. Successful recovery may be determined by early intervention and the individual's level of resilience. In addition, it is critical to conduct regular assessment of officers to ensure timely treatment. Attitude, preparedness, and social support play a role in a successful recovery. Additionally, officers may be at a greater risk for subsequent distress when a greater personal threat is perceived during a critical incident (McCaslin et al., 2006).

While research has examined the psychological trauma and resilience experienced by police officers, there have been very few research studies involving ambushes. Due to the continued risk of ambushes on police officers, gaining insight into the trauma and resilience of officers during these types of situations would be beneficial in providing psychologists with information in order to treat officers involved in an ambush and similar unprovoked attacks. 


\section{Trauma}

A traumatic stressor, also referred to in the literature as a "potentially traumatic event," is defined as "Any event (or events) that may cause or threaten death, serious injury, or sexual violence to an individual, a close family member, or close friend" (American Psychiatric Association, 2013, p. 830). Prior to 1970 , it was thought that individuals who did not have a family history of mental illness may only develop acute psychological distress if exposed to a traumatic event and recover without long-term effects (Jones \& Wessely, 2006). Any person suffering from the long-term effects of trauma was considered to have come from a "degenerate family" and was constitutionally vulnerable. However, during the Vietnam War, it was discovered that even healthy soldiers could suffer from chronic, adverse effects after being subjected to stress. It was also found that these effects may not have been clear at the time of their exposure to the stress. This came to be known as "delayed stress syndrome." It was not until 1980 that post-traumatic stress disorder (PTSD) was added to the Diagnostic and Statistical Manual of Mental Disorders (DSM) - Third Edition.

In the current version, DSM - Fifth Edition (DSM-5), PTSD is the diagnosis for individuals who have been exposed to "actual or threatened death, serious injury or sexual violence” (DSM-5, American Psychiatric Association, 2013, p. 271). These individuals can experience this type of exposure in four different ways: direct experience of the traumatic event, witnessing the event occur to others, learning of a traumatic violent or accidental event that occurred to a close family member or friend, or experiencing aversive details of a traumatic event repeatedly or having extreme exposure to those details. Individuals must also experience a disturbance for more than one month in the following categories: intrusion, avoidance, negative alterations in mood, and alterations in arousal and reactivity. These disturbances must either 
cause a clinically significant level of distress or impairment to the individuals in occupational, social, or other important areas of functioning (DSM-5, American Psychiatric Association, 2013). Additionally, the disturbance must not be attributable to another medical condition or substance use. Symptoms of PTSD include intrusive memories, recurrent distressing dreams, flashbacks, avoidance of thoughts and situations, memory loss of event(s), irritable behavior, hypervigilance, and feelings of fear, anger, or guilt (DSM-5, American Psychiatric Association, 2013). Symptoms of PTSD usually begin within three months of the traumatic event. However, it is possible that there is a delay of months or years before criteria can be met for a diagnosis. The term "delayed expression" is used to indicate that some symptoms may appear immediately, but the delay is with meeting the full criteria for the diagnosis (DSM-5, American Psychiatric Association, 2013).

It is common for an individual's reaction to a traumatic event to initially meet criteria for acute stress disorder immediately after the traumatic event. According to the DSM-5, the projected lifetime risk for PTSD at the age of 75 in the United States is 8.7 percent. It can occur at any age and is more prevalent in women than men. The risk of suicide for individuals with PTSD is higher for traumatic events such as childhood abuse (DSM-5, American Psychiatric Association, 2013). Suicidal ideation and suicide attempts are associated with PTSD. According to Hartley, Sarkisian, Violanti, Andrew, and Burchfiel (2013), PTSD may have an impact on an individual's physical as well as psychological health. Symptoms of PTSD have been significantly associated with greater frequency and severity of pain, poorer physical healthrelated quality of life, and increased general health symptoms and conditions. Additionally, it is also associated with cardiorespiratory and gastrointestinal complaints. With respect to 
psychological health, individuals with PTSD may also have comorbid psychological disorders. These include anxiety, depression, substance abuse, and addiction.

It is important to note that not everyone reacts the same way to potentially traumatic events (Bonanno \& Mancini, 2012). Some individuals will be unable to recover from the acute stress that they experience, while others suffer for a shorter period of time and less intensely (Bonanno, 2004). The DSM-5 lists risk factors that are divided into pretraumatic, peritraumatic, and posttraumatic factors (American Psychiatric Association, 2013). Pretraumatic risk factors are present prior to the traumatic event and increase the likelihood of experiencing traumatic symptoms. Some of these risk factors include prior mental disorders, low socioeconomic status, lower intelligence, and exposure to prior trauma. Peritraumatic risk factors are those that occur around the time of the traumatic event and increase the likelihood of experiencing traumatic symptoms. Some peritraumatic risk factors include severity of the trauma, perceived life threat, personal injury, and interpersonal violence. Posttraumatic risk factors occur after the traumatic event and increase the likelihood of experiencing traumatic symptoms. Some posttraumatic risk factors include negative appraisals, inappropriate coping strategies, exposure to repeated upsetting reminders, and other trauma-related losses.

According to findings in the research conducted by Tierens et al. (2012), posttraumatic reactions can also be experienced by witnesses of traumatic events. Their study examined the differences in posttraumatic stress reactions between witnesses and victims of motor vehicle accidents. The results indicated that witnesses of motor vehicle accidents reported significantly less internalizing symptoms. These symptoms include posttraumatic stress, fear, and depression. However, when compared to individuals who were never exposed to a motor vehicle accident with injury, the witnesses reported more externalizing symptoms, such as aggressive and rule- 
breaking behaviors. These results suggest that witnesses may also be at risk for developing posttraumatic stress reactions.

After reviewing the pretraumatic, peritraumatic, and posttraumatic risk factors, it is not surprising that police officers are at an increased risk of experiencing traumatic symptoms. Patterson (2001) conducted a study to examine the relationship between demographic variables and number of traumatic incidents among police officers. It was found that police officers experience an average of over three traumatic events every six months. These traumatic events may include armed conflicts, abusive violence, providing assistance to victims, and handling dead bodies (Hartley et al., 2013). According to findings in the research conducted by Hartley et al. (2013), frequency, recency, and type of traumatic events were associated with PTSD symptoms among LEOs. The results indicated that 60.1 percent of men and 46.4 percent of women police officers witnessed or were involved in five or more traumatic events within the past year. Additionally, it was found that over three-quarters of the police officers reported experiencing a traumatic event within the last month. Significant associations were also found between the frequency of traumatic events and PTSD symptoms in female police officers. However, the prevalence of PTSD between male and female police officers was similar.

Since police officers are frequently exposed to traumatic events, it is important to determine the effects these events have on them. Leigh Wills and Schuldberg (2016) examined the impact of work environment stress, cumulative exposure to traumatic events, and posttraumatic stress symptoms on personality traits of police officers. The traits were examined from baseline to five to ten years later. The results indicated that the mean scores of the personality traits of well-being, good impression, independence, and empathy declined. The 
decline in these traits were moderately- to highly correlated with posttraumatic stress symptoms. However, they were not correlated with the traumatic event exposure.

A study conducted by Leigh Wills and Schuldberg (2016) examined the impact of cumulative occupational exposure to traumatic events, posttraumatic stress symptoms, and work environment stress on personality traits over time. The results found that every police officer included in the study reported substantial traumatic event exposure. Additionally, the results showed that job-related traumatic events were negatively correlated with empathy and work environment stress was significantly related to gender. Specifically, female officers reported higher levels of operational and organizational stress.

As previously discussed, not everyone reacts the same way to traumatic events. Pietrzak et al. (2014) conducted a study to examine the trajectories of PTSD risk and resilience in responders of the World Trade Center. The sample included 4,035 police responders and 6,800 non-traditional responders (e.g., construction workers). It was found that among police responders, four classes best characterized the PTSD symptom trajectories. These four classes of trajectories were resistant/resilient trajectory, chronic symptom trajectory, recovering trajectory, and delayed-onset symptom trajectory. It was found that the majority of police officers $(77.8 \%)$ were in the resistant/resilient trajectory. Additionally, it was found that $8.5 \%$ were in the delayed-onset symptom trajectory, $8.4 \%$ were in the recovering trajectory, and $5.3 \%$ of officers were in the chronic trajectory. Researchers also found there was a strong association between the symptomatic trajectories and individuals who had prior psychiatric history, were of Hispanic ethnicity, severity of their exposure, and had World Trade Center-related medical conditions. The resistant/resilient trajectory will be discussed further in the next sections. 


\section{Resilience}

Resilience refers to the ability of adults who are exposed to potentially traumatic events to maintain healthy and stable levels of psychological and physical functioning (Bonanno, 2004). Individuals who are resilient may experience traumatic symptoms for a short period of time after being exposed to a traumatic event, but generally return to normal functioning over time. They also have the capacity for positive emotions and generative experiences following a traumatic incident. This response to potential trauma is often the most common response (Bonanno \& Mancini, 2012). Smith, Epstein, Ortiz, Christopher, and Tooley (2013) reported that there may be three different stages associated with rebounding from stress. The first stage of resiliency is confronting the event that is causing stress. The second step involves orienting oneself towards a future outcome that is positive. The third stage is engaging in an effort to cope with it. However, these stages do not have to occur in that particular order, and people may go back and forth between them.

Smith, Tooley, Christopher, and Kay (2010) conducted a study to examine the construct of resilience in predicting health-related measures while controlling for other positive characteristics. The health-related measure pertained to physical symptoms, perceived stress, and positive and negative affect. The other positive characteristics that were examined in this study were optimism, mood clarity, purpose in life, social support, and spirituality. The results indicated that resilience was related to less negative affect and more positive affect after controlling for the other positive characteristics. It also showed that resilience was related to less physical symptoms and less perceived stress after controlling for the other positive variables. These findings suggest that resilience is positively related to affective and physical health. 
Since resilience is related to bouncing back from stress, it is important to study resilience in police officers because they experience such a high level of stress and increased exposure to potentially traumatic events. Balmer, Pooley, and Cohen (2014) examined the relationships among resilience, coping style, psychological functioning, and several demographic variables among police officers. The demographic variables were gender, age, rank, and length of service. The results of this study showed that the greater use of rational coping and lesser use of emotional coping predicted resilience. This finding suggests that approach-based coping strategies are effective and may promote resilience. Balmer et al. (2014) also found that lower resilience scores were significantly correlated with increased age, rank, and length of service among police officers. This could be due to the cumulative exposure to traumatic incidents during their careers.

A study conducted by Rice and Liu (2016) explored the relationship between coping and resilience among active United States military members and veterans in order to identify the most effective coping strategies. The results indicated that greater positive reframing and less self-blame predicted higher levels of resilience. They also found that greater use of humor and less self-blame predicted greater resilience in military members.

Another study was conducted that examined positive psychological factors and posttraumatic stress symptoms among police officers (McCanlies, Mnatsakanova, Andrew, Burchfiel, \& Violanti, 2014). In this study, researchers examined the associations among resilience, satisfaction with life, gratitude, posttraumatic growth, and posttraumatic stress symptoms in police officers in New Orleans after Hurricane Katrina. The results of this study showed that lower posttraumatic stress symptoms were associated with higher levels of resilience, satisfaction with life, and gratitude. However, posttraumatic symptom levels were not 
associated with posttraumatic growth. It is also important to note that resilience scores decreased as levels of alcohol use among officers increased. This shows the importance of healthy coping strategies.

There have been several studies that assess trajectory of resilience among police officers. Galatzer-Levy et al. (2013) followed officers from training through 48 months of active duty. They assessed the officers' levels of distress every 12 months. The researchers identified four trajectories of resilience and distress among these officers. The four trajectories were resilient, reactive worsening, chronic distress recovering, and anticipatory distress recovered. The resilient trajectory includes individuals described as being asymptomatic or having low symptoms over time. The reactive worsening trajectory is categorized by consistent growth in distress that slowed slightly over time. The chronic distress recovering trajectory is described as experiencing a sharp increase in distress followed by a decrease. Finally, the anticipatory distress recovered trajectory was described as officers reporting high initial distress followed by a slow and consistent decrease. Galatzer-Levy et al. (2013) found that officers in the resilient trajectory reported lower levels of negative emotion during the academy. These results suggest that lower levels of negative emotion and higher levels of positive emotion prior to exposure to active duty stressors predict resilience.

Burke and Shakespeare-Finch (2011) conducted a longitudinal study that examined the effects of exposure to traumatic events prior to becoming a police officer. The officers were followed from the time they entered the police academy until the completion of 12 months on the job, representing a span of 20 months. The officers were placed into a trauma group (43\%) or no trauma group (57\%). The results indicated that having a prior trauma experience before entering the police force had an impact on officers' experience of potentially traumatic events. The results 
suggest that the prior trauma may have had a positive impact on the way trauma and stress are conceptualized with respect to the operational nature of the job. It may also suggest that prior exposure may facilitate adaptive responses to future traumatic events.

As discussed in the previous section, the study conducted by Pietrzak et al. (2014) found that the majority $(77.8 \%)$ of police officers were in the resistant/resilient trajectory when looking at posttraumatic stress symptoms following the World Trade Center collapse. The police responders were significantly less likely than non-traditional responders to have elevated patterns of posttraumatic symptoms. This finding is likely related to the high level of training and preparedness of police officers with respect to responding to traumatic events.

Due to the research finding that higher levels of resilience correlate with lower levels of posttraumatic stress symptoms, some police departments are starting to implement resilience training. Many studies have examined the effectiveness of resilience training among police officers. Weltman, Lamon, Freedy, and Chartrand (2014) conducted a case study to test the impact of a self-regulation and resilience-building program with law enforcement personnel. The intervention program, Stress Resilience Training System (SRTS), teaches the participants about resilience and its effects, as well as self-regulation techniques. The SRTS is presented on an iPad app. After finishing the training and using the SRTS app, each participant communicated with certified Personal Resilience Mentors over a four-week period. The results of this study indicated that scores on all four of the main scales (emotional vitality, organizational stress, emotional stress, and physical stress) showed improvement after the training. Additionally, the most important finding was that the subscale of stress under the organizational stress scale improved approximately $40 \%$ after the training. 
According to Papazoglou and Andersen (2014), training programs for police officers are not standardized. Current training programs focus on a militaristic style, developing communication skills, and working independently and as a team. These training programs need to include education for officers on the potential physical and mental health effects caused by exposure to chronic traumatic events and stressors (Papazoglou \& Andersen, 2014). Additionally, it is important to include information about the normalization of help-seeking behaviors after being exposed to a traumatic event, as well as the benefits of social support.

According to McCraty and Atkinson (2012), resilience building training has been shown to improve police officers' ability to recognize and self-regulate their responses to work and personal stressors. After completing the resilience building training, officers reported experiencing increased peacefulness and vitality and reductions in stress, negative emotions, and depression. The results of their study suggested that training in self-regulation and resilience building could have significant benefits for police organizations. These benefits include improving judgment and decision making, decreasing the frequency of duty-related driving accidents, and the use of excessive force in situations that provoke high stress.

\section{Violent Encounters}

It is widely known that law enforcement is a dangerous profession. Not only are officers at risk for accidents and illness related to their work, they are often the victims of intentional assaults (Schouten \& Brennan, 2016). These assaults can result in serious injuries or death. They can occur at many times during an officer's work day such as during arrests, investigations, or pursuit of suspects. The majority of the time, these assaults are unplanned and arise in an effort to resist arrest (Schouten \& Brennan, 2016). 
There have been many studies that examine violent encounters of police officers. Specifically, the Federal Bureau of Investigation's Law Enforcement Officers Killed and Assaulted (LEOKA) Program completed three research studies in order to help train officers throughout the country. The first study, "Killed in the Line of Duty," examined the offender motives associated with felonious killings of law enforcement officers (LEOs) to attempt to determine why they happened (United States Department of Justice, 1992). The second study, "In the Line of Fire," examined both offender motive and officer perceptions with respect to assaults on LEOs (United States Department of Justice, 1997). The third study, "Violent Encounters," combined the two previous studies and examined offender motive, officer perceptions, and the circumstances surrounding the killings and assaults of LEOs (United States Department of Justice, 2006). These studies are important in determining how and why these attacks occur. However, it is important to examine the psychological effects that these assaults have on police officers.

Impact of Violent Encounters. Law enforcement officers are often exposed to dutyrelated accidents and assaults (Schouten \& Brennan, 2016). These encounters often result in serious injuries or even death. Studying the impact of violent encounters on LEOs is vital because it not only affects the lives of police officers, but the general public. According to Crosby and Lyons (2016), “even though these killings account for a small percentage of total U.S. homicides, they represent a significant public health burden and can incite further violence in which more people are killed" (p.1).

Examining the impact of violent encounters on police officers is also important because officers typically experience a high number of events that pose a personal threat. Weiss et al. 
(2010) found that $15.9 \%$ of all police officers reported having been seriously assaulted at least once while on duty.

A study conducted by McCaslin et al. (2006) examined whether or not reports of personal threat during a critical incident contributed to the prediction of greater peritraumatic distress and posttraumatic symptoms. After being asked to provide a narrative of their most distressing critical incident, five classifications were revealed: personal life threat, duty-related violence, encountering physical or sexual assault victims, exposure to civilian death, and other. The results indicated that the officers whose critical incident was in the categories of duty-related violence or personal life threat had higher mean scores for hyperarousal symptoms than the officers whose critical incident was in the civilian death category. Additionally, the results showed that higher levels of peritraumatic dissociation and peritraumatic distress were reported by officers whose critical incident had a high level of personal threat. These officers also reported experiencing significantly greater hyperarousal symptoms within the past week. However, they did not report greater intrusion or avoidance symptoms.

Trauma. As discussed in the previous section, incidents that have a high level of personal threat are more distressing to officers than those that do not pose a personal threat. Violent encounters experienced by police officers pose a significant personal threat to them. Hartley et al. (2013) found a significant and positive association between being involved in a shooting and increased posttraumatic stress symptom scores for female officers. A study conducted by Prati and Pietrantoni (2010) examined the risk and resilience factors of officers exposed to critical incidents. With respect to risk factors of trauma, they grouped individuals by identifying different patterns of risk factors. Those risk factors were degree of exposure to critical incidents, peritraumatic distress, and perceived personal threat. The results showed that 
officers in the non-resilient group had lower levels of protective factors and higher levels of risk factors.

Another study conducted by Ellrich and Baier (2015) examined pretraumatic, peritraumatic, and posttraumatic risk factors of posttraumatic stress symptoms of officers who were violently assaulted. Some examples of these risk factors are trauma severity, psychological adjustment, and social support. The results found stronger stress symptoms associated with more severe trauma and more initial reactions showed by the officer. Initial reactions included displaying negative emotional responses such as helplessness, guilt, fear, and shame. The emotional reactions were assessed by asking the police officers questions about their perception of the attack, including if the attack was premeditated in order to injure the officer, and feelings of responsibility. It was also found that facing legal consequences from the assault is a risk factor of posttraumatic stress because it may constitute secondary victimization. An allegation of wrongdoing by the officer can lead to a role reversal of being the victim versus the offender, which adds a subsequent level of victimization. Additionally, attacks that were motivated by animosity toward the police were associated with high posttraumatic stress symptoms.

A study conducted by Ménard and Arter (2013) examined the relationships among critical incidents, negative coping, social stressors, problematic alcohol use, and posttraumatic stress symptoms after controlling for demographics. The results of this study showed that alcohol use and posttraumatic stress symptoms were significantly and positively related. Negative coping and social stressors were also significantly and positively related to alcohol use. These results are not surprising because alcohol use is a common negative coping strategy. Critical incidents, negative coping, and social stressors were positively and significantly related to PTSD. Increased PTSD symptoms were also related to the use of avoidance coping strategies used by officers. 
Avoidant coping strategies included failure to discuss emotions, self-criticism, social withdrawal, and failure to seek professional assistance. Additionally, officers with less experience were more likely to report symptoms of PTSD. These results suggest that these newer officers may not have yet developed the skills to be able to deal with some of the hazards of the job.

Resilience. In the article by Prati and Pietrantoni (2010) that examined the risk and resilience factors of officers exposed to critical incidents, the authors found that there were two types of protective factors: social support and self-esteem. The results showed that officers that exhibit lower peritraumatic distress, lower perceived threat, higher self-esteem, and higher social support had the tendency to report less PTSD symptoms. Additionally, this finding is irrespective of the officers' critical incident exposure. The results of this study indicate that protective and risk factors seem to be more important for health outcomes than the degree of exposure to critical incidents. According to Prati and Pietrantoni (2010), the results of this study demonstrate that an environment which is socially supportive may enhance an individual's resilience from traumatic experiences. This is accomplished by exploration in an atmosphere that is non-judgmental, sharing negative emotions, normalization, and the encouragement of discussion. In the study conducted by Ellrich and Baier (2015) which examined pretraumatic, peritraumatic, and posttraumatic risk factors of posttraumatic stress symptoms of officers who were violently assaulted, it was found that good psychological adjustment was a protective factor against posttraumatic stress.

\section{Ambushes}

According to De Groot and Fachner (2014), since 1990 ambushes appear to be a growing trend among police officers who are feloniously killed. From 2008 to 2012, ambushes comprised of 15 to 32 percent of police deaths. In 2011, the United States Attorney General reported that 
more work was needed on initiatives that make an impact on officer safety (IACP, 2014). These initiatives include identifying protocols and tactics to protect law enforcement officers from ambushes. According to Fachner and Thorkildsen (2015), resources and lack of in-house expertise are the biggest barriers to providing adequate training. Additionally, in-depth analyses of past critical incidents are difficult to find. This is because most reports are news bulletins which only present the basic facts.

The Federal Bureau of Investigation's Uniform Crime Report (UCR) defines an ambush against a law enforcement officer (LEO) as:

Assigned or on-view activities where the officer is assaulted, unexpectedly as the result of premeditated design by the perpetrator(s). Ambushes are further broken down into two categories: (1) ambushes that include entrapment and premeditation and (2) ambushes that include a spontaneous or unprovoked attack" (Daniels et al., 2019, p. 7)

Ambushes that include premeditation and entrapment are those in which an offender plans to draw an unsuspecting officer into a situation and attack them (IACP, 2014). Spontaneous ambushes are characterized by deciding to attack an officer at the time of the officer's approach. These are often considered crimes of opportunity. Additionally, there are generally four factors that define an ambush. These factors are the element of surprise, concealment of the assailant, their intentions, or weapon, suddenness of the attack, and lack of provocation (IACP, 2014).

There have been a limited number of studies related to ambushes. According to the International Association of Chiefs of Police (2011), an ambushed officer is most likely to be a patrol officer (38\%), deputy sheriff (17\%) or sergeant (15\%). These officers are typically male and have an average age of 38 years old with 11 years of experience. Additionally, these officers are most likely to be alone during the ambush (82\%). An assailant of an ambush is typically 30 
years of age with a prior criminal record $(75 \%)$. The majority of offenders act alone (83\%). The most commonly used weapon during an ambush is a firearm. A study conducted by the Federal Bureau of Investigation (2016) examined assailants' mindset and behavior. Assailants included in the study had several common characteristics. Eighty-six percent of the assailants in the study had a prior criminal history. Additionally, fifty-six percent of these individuals were previously known to the local law enforcement departments. Eighteen percent were diagnosed with mental health issues. All of the assailants were males between the ages of 14 and 68 years old. There were found to be two main reasons for the attacks: the individual expressed a desire to kill law enforcement, and the individual felt as though they were going to go back to jail and lose their freedom.

A study conducted by Daniels et al. (2019) examined the who, what, and why of ambushes in order to try to prevent them. This study included interviews of both offenders and officers, depending on who survived the ambush. With respect to offenders, motives and background factors were examined. While analyzing the information presented by officers, the circumstances and perceptions of the officers were examined. Officers included victim officers and witness officers. Individuals included in the victim officer group were law enforcement officers (LEOs) who were injured during an ambush and the witness officer group was comprised of LEOs who witnessed another officer being killed or injured, but were not injured themselves, during an ambush. With respect to examining the background factors of offenders, the preliminary results of this study indicated that the offenders were most often male, a racial minority, averaging 28 years of age, and had a history of drug and/or alcohol abuse. Additionally, the majority of the offenders had a prior criminal history and one or more past suicide attempts. One third of the offenders had prior confrontations with police. It is important 
to note that this sample was a convenience sample including offenders who survived, were convicted, and agreed to be interviewed about the ambush.

The preliminary results regarding the circumstances and perceptions of officers revealed that there were several common themes in the qualitative research (Daniels et al., 2019). Those themes included altered perceptions, can't see offender, confusion, physiological reactions, and tunnel vision. Assisted by other LEO, approached by offender, and bystander involvement were also common themes found by the research team. Altered perceptions was defined as feeling as though time was altered or there was an altered perceptual acuity. Can't see offender was defined as not knowing where the attack was coming from and being unable to see the offender.

Confusion was described as initial confusion of the LEO when the attack began. "Physiological reactions" was defined as the LEOs bodily reaction or sensation at the time of the ambush. Tunnel vision was described as the LEO being very focused during the ambush. Despite what we have learned about LEOs who have been ambushed, there have not been any studies related to trauma or resilience with respect to ambushes. This research study will fill the gap in the research literature pertaining to the trauma and resilience of officers involved in an ambush.

\section{Purpose}

Given the reviewed research, this study aimed to examine the differences in symptomatology of trauma and level of resilience among victim and witness police officers involved in an ambush. Initially there were two research questions and hypotheses to this dissertation:

Research Question 1. Does an officer's involvement in an ambush have an impact on their level of trauma symptomatology? 
H1: Victim officers will report greater levels of symptomatology than witness officers on a trauma measure after controlling for time since the ambush.

Research Question 2. Does an officer's involvement in an ambush have an impact on their level of resilience?

$\mathbf{H}_{2}$ : Victim officers and witness officers will score significantly different on a measure of resilience after controlling for time since the ambush. A nondirectional hypothesis was chosen because there is no previous research to predict the direction of the effect.

However, due to limitations of the sample that will be described in subsequent chapters, the following revised hypotheses were tested:

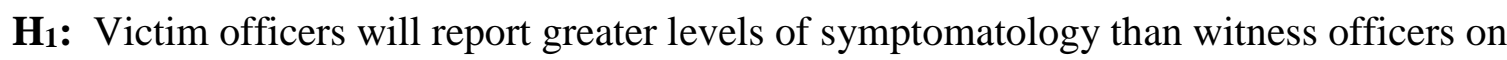
a trauma measure.

$\mathbf{H}_{2}$ : Victim officers and witness officers will score significantly different on a measure of resilience after controlling for time since the ambush. 


\section{Chapter 2: Methods}

The purpose of the proposed study was to examine the differences in symptomatology of trauma and level of resilience among police officers involved in an ambush. Specifically, the goal of this study was to examine the differences between victim officers and witness officers with respect to trauma and resilience while controlling for the time since the ambush. It was first hypothesized that victim officers would report greater levels of symptomatology on a trauma measure after controlling for time since the ambush. Additionally, it was hypothesized that victim officers and witness officers would score significantly different on a measure of resilience after controlling for time since the ambush.

The purpose of this study was not met because the sample size was not large enough to conduct the analyses to examine the original hypotheses. As a result, the hypotheses were changed to the following:

H1: Victim officers will report greater levels of symptomatology than witness officers on a trauma measure.

H2: Victim officers and witness officers will score significantly different on a measure of resilience.

The data analyses were also changed to conduct an exploratory study. This chapter includes details regarding the specific research design and methodology that were used to examine these two hypotheses.

\section{Design}

In order to determine if there were significant differences in levels of symptomatology of trauma and levels of resilience among police officers involved in an ambush, a between-subjects design was used. There was one independent variable with two groups and two dependent 
variables. The design was a quasi-experimental design because the participants were not randomly assigned to their groups. Specifically, a post-test nonequivalent group design was used. According to Heppner, Wampold, and Kivilighan (2008), "These groups are referred to as nonequivalent because participants have generally been assigned to a group prior to the research being conducted" (p. 180). The independent variable of officer status was comprised of two groups and based on the officer's involvement in the ambush. The two groups within officer status were victim officers and witness officers. Victim officers were law enforcement officers (LEOs) who were injured during an ambush and witness officers were LEOs who witnessed another officer being killed or injured, but were not injured themselves, during an ambush.

\section{Participants}

Participants for this study were required to be men and women, 18 years of age or older who were current or past sworn law enforcement officers in the United States. Following the requirements to be included in the Federal Bureau of Investigation's Law Enforcement Officers Killed and Assaulted Program (Federal Bureau of Investigation [FBI], 2016) data collection, the participants were required to have been employed as a sworn law enforcement officer within a city, university or college, county, state, tribal, or federal agency during the time of the ambush. To be included in the study, the officer must have met the following additional criteria: wore or carried a badge, carried a firearm, was duly sworn and had full arrest powers, was a member of a public governmental law enforcement agency and was paid from government funds set aside specifically for payment to sworn law enforcement, and was acting in an official capacity, whether on or off duty, at the time of the incident. The following education levels were assessed for participants: high school, General Equivalency Degree (GED), 2-year college, 4-year college, 
or graduate degree. These individuals were sorted into two different groups: victim officers and witness officers, depending on their involvement in the ambush.

Prior to beginning data collection, the minimum number of participants needed to complete this study was determined by conducting an a priori power analysis using G*Power 3 (Faul, Erdfelder, Lang, \& Buchner, 2007). It was originally planned to complete an ANCOVA, which needed a total of 128 participants with 69 participants in each of the two groups. Due to difficulty with data collection, the data analyses changed to an independent samples t-test. The a priori power analysis was conducted again to determine the minimum number of participants needed to complete the revised data analyses. The statistical test entered was an independent samples t-test with one tail, a medium effect size of 0.50 , a power of 0.80 , and an alpha of .10 (Faul et al., 2007) were established. These parameters were chosen because the study includes one independent variable (officer status) with two groups (victim officers and witness officers) and two dependent variables (trauma and resilience). The effect size and statistical power used are consistent with previous studies comparing victims and witnesses of a traumatic event (Tierens et al., 2012). The results of the power analysis indicated that a minimum total sample size of 72 participants would be needed. Since the study includes two different groups, this study aimed to have approximately 37 participants in each of the two groups. A convenience sample was used to conduct this study.

The participants for this study were recruited by contacting seventeen police organizations. After one month of data collection, only nine participants completed the entire questionnaire. Since there were not enough participants after one month of data collection, additional measures were taken to recruit more participants. The subsequent attempts at collecting data yielded an additional ten participants who completed the entire questionnaire. The 
total number of participants obtained after three months of data collection was 19 officers. As a result, the hypotheses and data analyses were changed to conduct an exploratory study. This process will be described in detail in the Procedures section.

\section{Independent Variable}

One independent (status) variable of officer status was assessed in this study. Officer status was divided into two groups: victim officer and witness officer. The victim officer group included law enforcement officers who were injured during an ambush. The witness officer group included law enforcement officers who witnessed another officer being injured or killed, but were not injured themselves, during an ambush.

\section{Dependent Variables (Measures)}

In an attempt to collect the necessary data to complete this study, three measures were used. This section includes a review of the measures, including their psychometric properties.

Impact of Event Scale - Revised (IES-R; Weiss \& Marmar, 1997). The IES-R is a 22item self-report measure used to assess an individual's level of symptomatic response to a specific traumatic event. This scale is comprised of three constructs including intrusion, avoidance, and hyperarousal. Participants rate each item on a 5-point Likert scale ranging from zero "not at all" to four "extremely." Example statements on the IES-R include, "Any reminder brought back feelings about it" and "I was aware that I still had a lot of feelings about it, but I didn't deal with them." Scale scores are formed for each of the three constructs by averaging the scores of each construct's corresponding items (Appendix A). For the purposes of this study, the total score was obtained to increase the variance among the scores of each participant.

A study by Creamer, Bell, and Failla (2003) examined the psychometric properties of the IES-R on a sample of male Vietnam veterans and found the items show a high level of 
intercorrelation, ranging from .52 to .87 . High levels of internal consistency reliability have been reported. The total scale yielded a Cronbach's alpha coefficient of 0.96 . The construct of intrusion includes eight items and has a Cronbach's alpha coefficient of .94 (Creamer et al., 2003). The construct of avoidance includes eight items and has a Cronbach's alpha coefficient of .87. Finally, the construct of hyperarousal includes six items and has a Cronbach's alpha coefficient of .91 . With respect to concurrent validity, the total score of the IES-R was highly correlated with the total score of the PTSD Checklist (PCL; Weathers, Litz, Herman, Huska, \& Keane, 1993) ( $r=.84$; Creamer et al., 2003). Additionally, initial examination of the psychometric properties by Weiss and Marmar (1997) found the test-retest reliability ranged from .89 to .94 across a 6-month interval (as cited in Creamer et al., 2003).

The original IES-R asked participants to indicate their level of distress during the past seven days on each of the items regarding a specific traumatic event. However, in a more recent study by Janson, Carney, Hazier, and Insoo (2009), the instructions were revised to ask witnesses of potentially traumatic events to rate their level of distress at the time of the event. The reliability of this study using the modified instructions was supported by a high degree of internal consistency of .90 (Janson, Carney, Hazier, \& Insoo, 2009). Thus, the revised version of the instructions was used for this study.

Brief Resilience Scale (BRS; Smith et al., 2008). The BRS is a 6-item self-report measure used to assess an individual's ability to recover from stress. Participants are asked to rate their level of agreement with statements regarding their ability to recover from a stressful event. Example statements on the BRS include, "I tend to bounce back quickly after hard times" and "It is hard for me to snap back when something bad happens." Each of the six statements are rated on a 5-point Likert scale ranging from one "strongly disagree" to five "strongly agree." 
Items 1, 3, and 5 are positively worded on the questionnaire while items 2, 4, and 6 are negatively worded, and are thus reverse scored. A total score is obtained by calculating the mean of all six items (Appendix B). For the purposes of this study, the total score of the six items were used. Due to the small sample size of this study, using the total score increased the variance among the scores of the participants. The psychometric properties were examined on four samples: two samples of undergraduate students, one sample of cardiac rehabilitation patients, and one sample of women who either had fibromyalgia or were healthy controls. The internal consistency reliability of the BRS was found to be high, with Cronbach's alpha coefficients ranging from .80 to .91 . The test-retest reliability was .69 after one month and .62 after three months. Convergent validity was demonstrated through the significant positive correlation of the BRS and Connor-Davidson Resilience Scale (CD-RISC; Connor \& Davidson, 2003), Ego Resiliency Scale (Block \& Kremen, 1996), Life Orientation Test-Revised (LOT-R; Scheier, Carver, \& Bridges, 1994), and Purpose of Life Test (Ryff \& Keyes, 1995). The correlations ranged from .51 to .67 .

Demographic questionnaire. This instrument was used to obtain demographic information from the participants. Participants were asked to answer questions about their gender, age at the time of ambush, race/ethnicity, level of education, work status, type of agency, rank in agency, years of police experience at time of ambush, date of ambush, type of assignment, involvement in ambush (victim or witness), status of victim officer, weapon used by offender, and counseling received after the ambush (Appendix C).

\section{Covariate}

Time since the attack was believed to be a covariate for this study. Because the amount of time since the attack occurred could have an impact on an individual's level of symptomatology 
on the dependent variables, time since the attack was originally considered a covariate for trauma and resilience. Due to the small sample size, the suspected covariate of time since the attack was not analyzed.

\section{Procedure}

In order to obtain participants for this study, the researcher started the process by contacting the Department of Justice's Office of Community Oriented Policing Services (COPS), the National Sheriff's Association, the FBI's National Academy Associates, and the United States Marshals Service Association and requesting their assistance. An email was sent to each of these organizations that included information describing the study and requesting the assistance in distributing the recruitment information via a listserv to members of their organization (Appendix D). The United States Marshals Service Association requested additional information and a letter was sent to present information to their Office of General Counsel (Appendix E). If the organization agreed to participate by sending the information via listserv, a recruitment letter was sent to be distributed via listserv (Appendix F) after obtaining approval from West Virginia University's Institutional Review Board (WVU IRB). This email included a link to the Qualtrics survey, requirements for participation, and informed consent (Appendix G). Additionally, in an effort to expand recruitment, information about the study was posted on the social media site, Facebook (Appendix H). After one month a data collection, 29 individuals completed the informed consent portion of the survey. However, of those 29 individuals, only 11 completed a portion of the questionnaire, with only nine of those 11 individuals completed the entire questionnaire. Since there were not enough participants to complete the study after one month, the researcher followed-up with the participating organizations and requested the email be sent through the listserv again. After the second attempt of recruiting additional participants, 
six more individuals completed the informed consent portion of the survey, four of whom completed the entire questionnaire.

Since there were not enough participants to complete the study after two months, the researcher contacted other law enforcement agencies and organizations by email in order to request their participation in recruiting participants for the study. Those law enforcement agencies and organizations included the West Virginia State Police, the Ohio State Highway Patrol, the North Carolina Highway Patrol, the West Virginia Fraternal Order of Police, the Ohio Fraternal Order of Police, the Pennsylvania Fraternal Order of Police, the Florida Fraternal Order of Police, the Texas Fraternal Order of Police, the New York Fraternal Order of Police, the Dallas Police Department, the New York City Police Department, the Chicago Police Department, and the Los Angeles Police Department. These organizations were sent the information describing the study and a request for assistance in distributing the recruitment information via a listserv. The email also contained a link to the Qualtrics survey, requirements for participation, and informed consent. Of those organizations, the Ohio Fraternal Order of Police was the only one that responded to the recruitment email and agreed to forward it to their members. The third attempt to recruit participants yielded 15 additional individuals that completed the informed consent. Of those 15 individuals, only six completed the entire questionnaire. Four individuals entered the survey but answered "no" to the informed consent and were directed out of the survey. Data collection was stopped after three months of data collection.

When the participant entered the Qualtrics website from the link provided, they saw a short description of the study and informed consent. If a participant did not meet the minimum requirements or declined to participate, they were directed to end the survey. If the participants 
met the minimum criteria and agreed to participate, they were asked to begin the questionnaire. At the beginning of the questionnaire the participants were asked to complete the IES-R and BRS, which were randomly counterbalanced to reduce the potential for order effects. It ended by asking the participants to complete the demographic questionnaire. After the participant finished answering the questions, they submitted their answers on the website.

After completion, the participant was directed to another page, which provided a poststudy form including the researcher's contact information for any questions they may have about the study and a list of mental health resources in case any adverse reactions were experienced from participating in the study (Appendix K). Finally, the participants had the option of entering into a drawing to win one of four $\$ 25$ Visa gift cards. If the participants wanted to be entered into the drawing, they were directed to a separate page where they were instructed to enter their email address. This information was kept separate from their questionnaire answers. After the survey was closed, four email addresses were selected using Random Picker, which is an online service that conducts random drawings. The four randomly selected individuals were each emailed a $\$ 25$ Visa gift card. The email addresses were deleted following the drawing for the gift cards. Participants of this study were only interacted with in the way that was approved by WVU IRB. Only participants who completed the BRS and IES-R, as well as met the minimum participation requirements were included in the data analyses.

\section{Analysis}

Due to difficulty with data collection, there were not enough participants to meet the criteria for the proposed quantitative analyses. As a result, the data analyses were changed to explore the data. Descriptive statistics were conducted for each of the demographic variables. Further, data analyses were conducted using correlations and independent samples $t$-tests. 
Assumptions for the independent $t$-tests were evaluated prior to analysis. This statistical test determined whether there were significant mean differences in the total scores on the Impact of Event Scale - Revised (IES-R; Weiss \& Marmar, 1997) and the Brief Resilience Scale (BRS; Smith et al., 2008) between victim officers and witness officers, as well as individuals who received counseling and those who did not receive counseling after the ambush.

The data collected during this study were analyzed using IBM's SPSS program (IBM, 2013). Descriptive statistics including means and standard deviations were calculated for age at the time of the ambush and years of police experience at the time of the ambush. Descriptive statistics including sums and percentiles were calculated for the demographic information including gender, race/ethnicity, level of education, work status, type of agency, rank in agency, type of assignment, involvement in ambush (victim or witness), status of victim officer, weapon used by offender, and counseling received after the ambush. A range was computed for the date of the ambush. Additionally, Pearson correlations were conducted for gender, age at the time of ambush, years of police experience at time of the ambush, involvement in the ambush, whether or not counseling was received after the ambush, IES-R total scores, and BRS total scores. The correlations were conducted to determine if there was a significant relationship between each of the variables (Salkind, 2011). Due to the small sample size, independent-samples $t$-tests were conducted. Before conducting the $t$-tests, the researcher attempted to ensure the statistical assumptions were met for each hypothesis.

There were several assumptions that needed to be met before conducting an independentsamples $t$-test (Field, 2009), including the following: continuous dependent variable, one independent variable with two categorical, independent groups, independence of observations, no significant outliers, normal distribution, and homogeneity of variances. The continuous 
dependent variable was met because the study used the total scores of IES-R and BRS as dependent variables. The assumption regarding one independent variable with two categorial, independent groups was met because the study used involvement in the ambush (victim officer or witness officer) as the independent variable. The independence of observations was assumed because two independent groups were used, and tests of independence were not conducted. Outliers were assessed by examining boxplot generated on SPSS. Normality was assessed by conducting the Shapiro-Wilk test in SPSS. The assumption of normality was also assessed by examining Q-Q plots generated in SPSS. Homogeneity of variance was tested by conducting a Levene's test in SPSS.

Hypothesis 1. Victim officers will report greater symptomatology on the IES-R than the witness officers. This hypothesis was tested with an independent samples $t$-test, with group membership (victim vs. witness) serving as the independent variable and scores on the IES-R entered as the dependent variable.

Hypothesis 2. Victim officers and witness officers will score significantly different on the BRS. This hypothesis was tested with an independent samples $t$-test, with group membership (victim vs. witness) serving as the independent variable and scores on the BRS entered as the dependent variable. A non-directional hypothesis was chosen because there is no previous research to predict the direction of the effect.

Since this study was changed to an exploratory study, additional analyses were also conducted. Independent samples $t$-tests were also conducted to assess whether there were significant differences in the total scores on the Impact of Event Scale - Revised (IES-R; Weiss \& Marmar, 1997) and the Brief Resilience Scale (BRS; Smith et al., 2008) between officers who received counseling and those who did not receive counseling after the ambush. The assumptions 
for the independent sample $t$-tests previously discussed were also assessed prior to conducting these additional analyses. 


\section{Chapter 3: Results}

\section{Descriptive Analyses}

The data for the study were collected during the Spring 2019 semester. The participant sample $(n=23)$ was comprised of victim and witness officers involved in an ambush. The race and ethnicity of the sample was primarily White/Caucasian $(n=19 ; 82.6 \%)$ and four officers did not specify $(17.4 \%)$. This sample included mostly males $(n=18 ; 78.3 \%$;), one female $(4.3 \%)$, and four did not specify $(17.4 \%)$. The average age of the sample was 36.3 years old $(S D=9.3)$ with a range of 22 to 60 years old. During the ambush, 15 officers were Victims (65.2\%), four were Witnesses (17.4\%), and four did not specify (17.4\%). With respect to level of education, one participant had a high school diploma (4.3\%), one completed a GED (4.3\%), three participants earned an Associate's Degree (13.0\%), eight participants earned a Bachelor's Degree (34.8\%), four earned a Master's degree (17.4\%), two participants marked Other (8.7\%), and four did not specify (17.4\%). Participants were also asked to provide information regarding their current work status. Of the participants, 15 are Full-Time (65.2\%), four are Retired (17.4\%), and four did not specify (17.4\%). Data were also collected for the type of agency. At the time of the ambush 10 officers were working for a City agency (43.5\%), six were employed by a County agency (26.1\%), three marked Other (13.0\%), and four did not specify (17.4\%). The average years of experience at the time of the ambush was 13.9 years $(S D=9.9)$ with a range of 2 to 38 years. The ambushes occurred between July 1979 and March 2019. Information on type of assignment during the ambush was also collected: 12 officers were working a One-Officer Patrol (52.2\%), two were working a Two-Officer Patrol (8.7\%), two were Investigative/Detection (8.7\%), one was Overtime/Extra Duties (4.3\%), and two marked Other (8.7\%). Information regarding the work status of the Victim Officer was collected: three victims 
are currently Retired (13.0\%), 16 victims Returned to Duty (69.6\%), and 4 did not specify (17.4\%). Data regarding the type of weapon used by the offender was collected. During the ambushes, 15 involved a Firearm (65.2\%), one involved a Blunt object (4.3\%), three involved Hands, Fists, Feet (13.0\%), and four did not specify (17.4\%). With respect to receiving counseling after the ambush, six indicated they did receive counseling (26.1\%), 13 indicated they did not receive counseling (56.2\%), and 4 did not specify (17.4\%). Since four individuals completed the two measures but not the demographics portion of the questionnaire, they were dropped from the subsequent analyses.

\section{Coding and Scoring}

The demographic variable "Involvement" was dummy coded ( $1=$ victim, $2=$ witness $)$. Additionally, the demographic variable of "Counseling” was dummy coded ( $1=$ no, $2=$ yes $)$. Total scores were calculated for the Impact of Event Scale - Revised (IES-R; Weiss \& Marmar, 1997) and the Brief Resilience Scale (BRS; Smith et al., 2008). The IES-R measures an individual's level of symptomatic response to a specific traumatic event. Individual responses were added together to produce a total score where higher scores represent greater levels of distress regarding the traumatic event. The average IES-R score for victims was $60.1(\mathrm{SD}=14.0)$ and the average IES-R score for witnesses was $56.0(\mathrm{SD}=17.3)$. The average IES-R score for individuals who did not receive counseling after the ambush was $59.5(\mathrm{SD}=15.0)$ and the average IES-R score for individuals who received counseling after the ambush was $59.2(\mathrm{SD}=$ 14.6).

The BRS measures an individual's ability to recover from stress, where higher scores reflect greater resilience. Responses to items 2, 4, and 6 were reversed scored. Total BRS scores were calculated by totaling the responses to each individual item on the test. The average BRS 
score for victims was $21.5(\mathrm{SD}=4.1)$ and the average $\mathrm{BRS}$ score for witnesses was $24.0(\mathrm{SD}=$ 4.8). The average BRS score for individuals who did not receive counseling after the ambush was $24.3(\mathrm{SD}=2.0)$ and the average BRS score for individuals who received counseling after the ambush was $20.9(\mathrm{SD}=4.6)$.

\section{Tests of Assumptions}

Involvement in Ambush. Six assumptions were checked before conducting the independent samples $t$-test for officer involvement: (1) continuous dependent variable; (2) one independent variable with two categorical, independent groups; (3) independence of observations; (4) no significant outliers; (5) approximately normal distribution; and (6) homogeneity of variances. The continuous dependent variable assumption was met because the IES-R and BRS provide continuous scores. The one independent variable with two categorical, independent groups assumption was met because involvement in the ambush consisted of victims and witnesses. The independence of observations assumption was met because there were different participants in each group of involvement in the ambush. Two boxplots were examined to determine if there were significant outliers. Each boxplot showed that there were no outliers. The IES-R scores were normally distributed for the victim group as evidenced by a ShapiroWilk's score of W(15) $=.973(p=.900)$ and witness group with a Shapiro Wilk's score of W(4) $=.986(p=.935)$. The BRS scores were normally distributed for the victim group as evidenced by a Shapiro-Wilk's score of W(15) =.922 $(p=.204)$ and witness group with a Shapiro Wilk's score of $\mathrm{W}(4)=.91(p=.488)$. In addition, four Q-Q Plots were generated. Figure 1 shows the Q-Q plot of IES-R total scores for victims; Figure 2 shows the Q-Q plot of IES-R total scores for witnesses; Figure 3 shows the Q-Q plot of BRS total scores for victims; and Figure 4 shows the Q-Q plot of BRS total scores for witnesses. Each figure shows the approximate normal 
distribution. Finally, a Levene's test revealed that the assumption of homogeneity of variances was met for the IES-R Total, $F(17)=.361, p=.556$ and the BRS, $F(17)=.423, p=.524$.

Figure 1

Q-Q Plot of IES-R Total for Victims

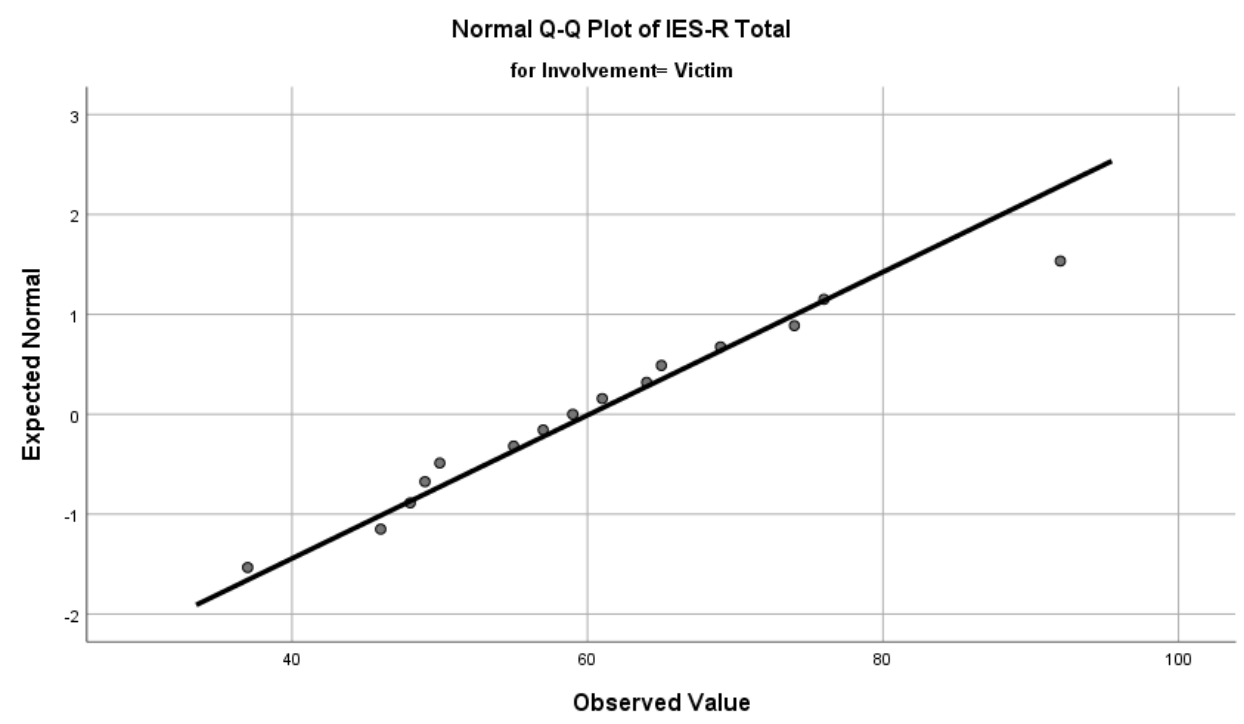

Figure 2

Q-Q Plot of IES-R Total for Witnesses

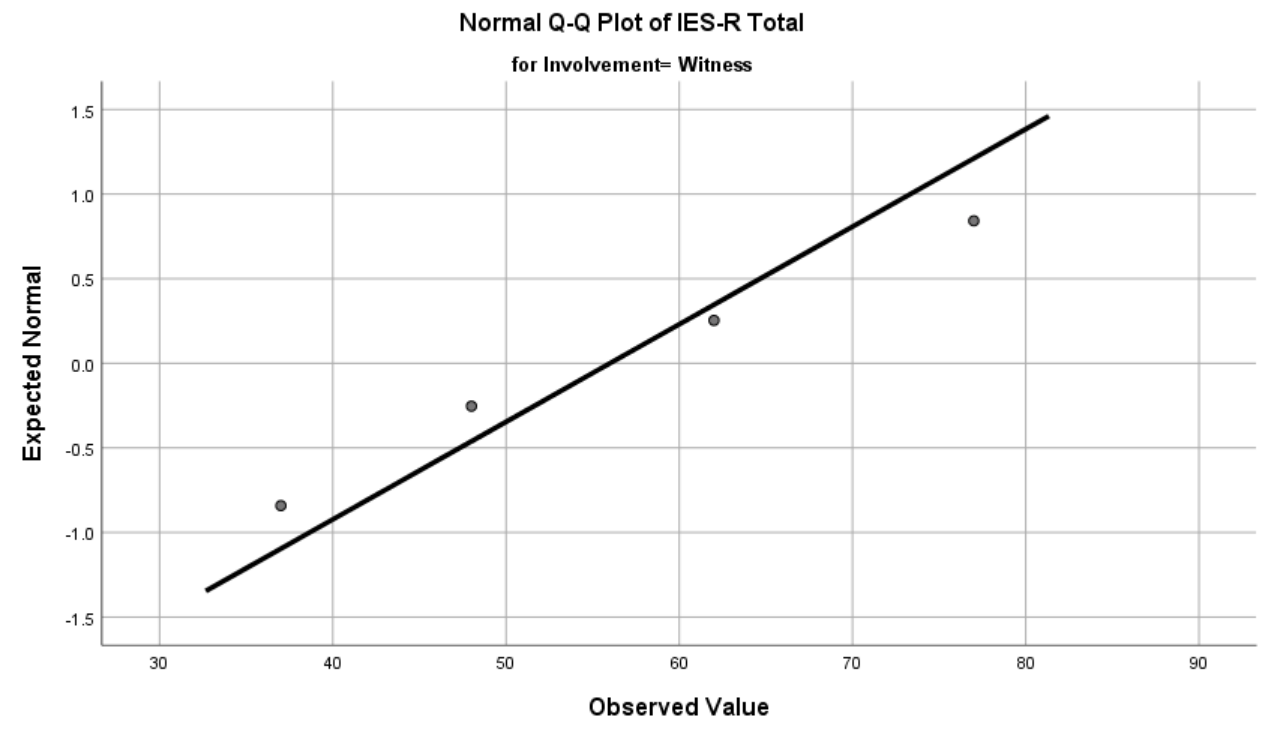


Figure 3

Q-Q Plot of BRS Total for Victims

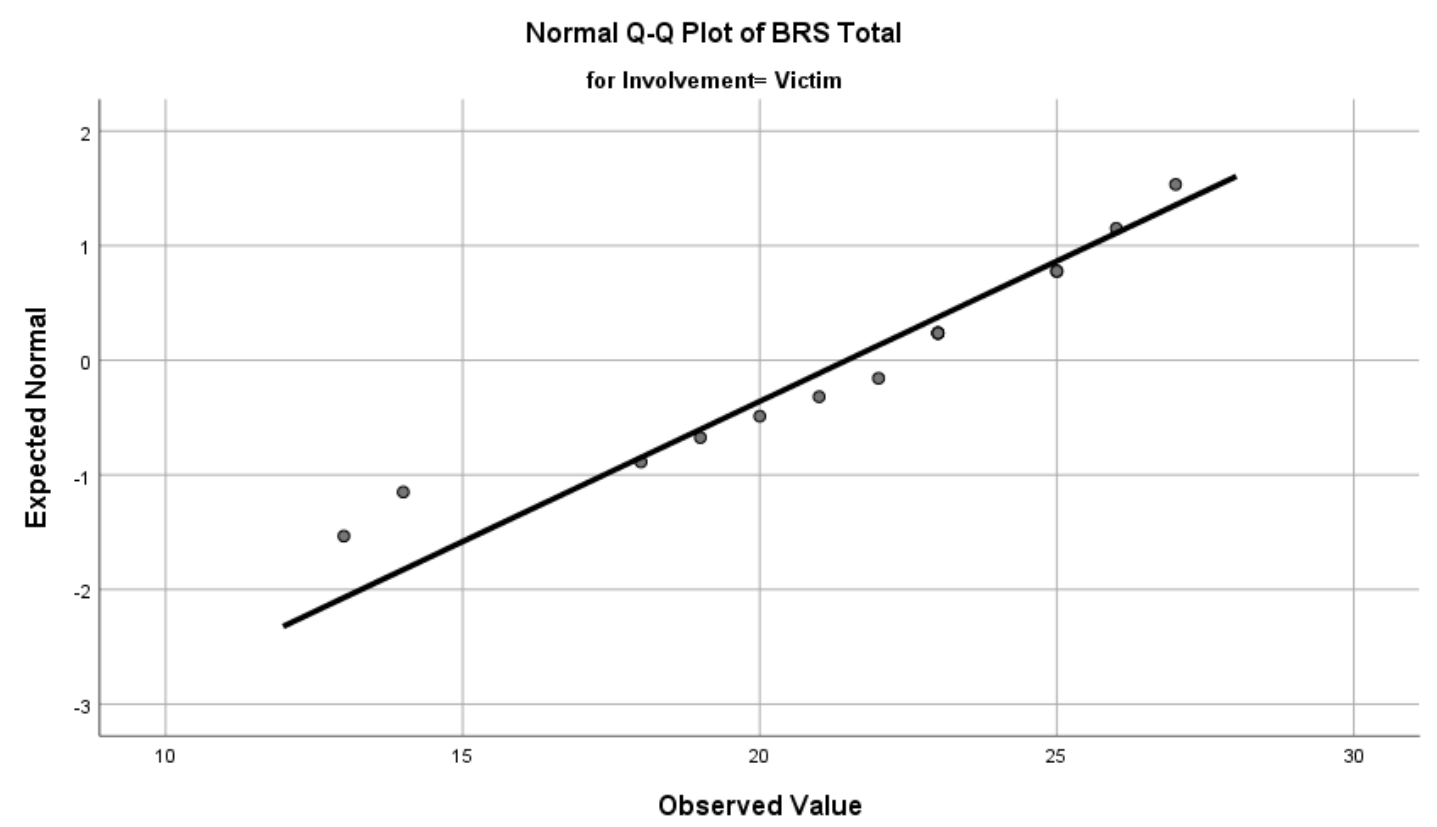

Figure 4

Q-Q Plot of BRS Total for Witnesses

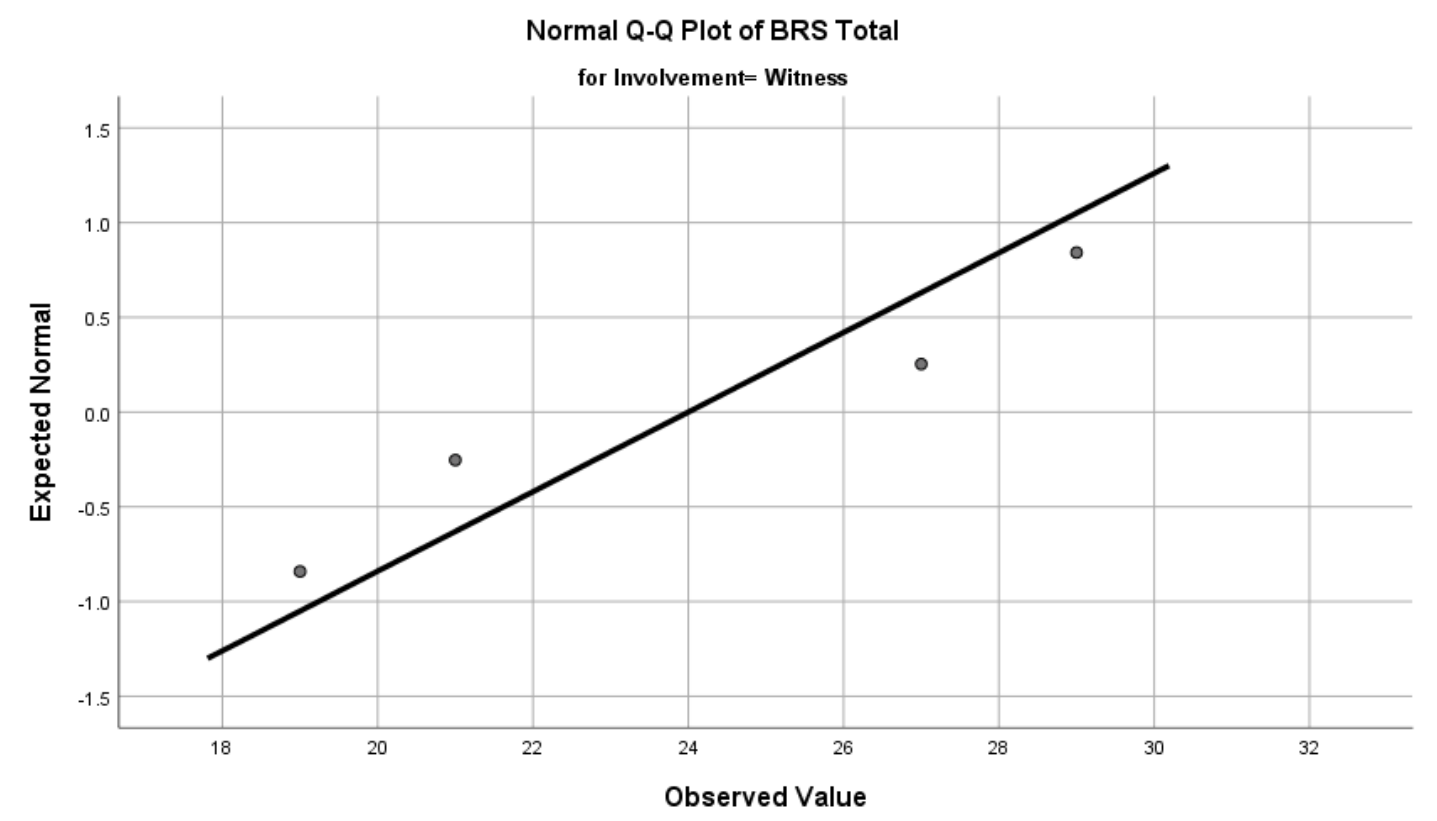


Counseling after the Ambush. The same six assumptions were checked before conducting the independent samples $t$-test for counseling after the ambush. The continuous dependent variable assumption was met because the IES-R and BRS provide continuous scores. The one independent variable with two categorical, independent groups assumption was met because counseling consisted of individuals who received counseling and individuals who did not receive counseling after the ambush. The independence of observations test was met because there were different participants in each group of counseling after the ambush. Four Q-Q Plots were generated, and two boxplots were examined to determine if there were significant outliers. Each boxplot showed that there were no outliers with the exception of the boxplot of IES-R Total and Counseling, which showed one outlier. The IES-R scores were normally distributed for the no counseling group as evidenced by a Shapiro-Wilk's score of W(6) $=.951(p=.746)$ and counseling group with a Shapiro Wilk's score of W(13) $=.955(p=.679)$. The BRS scores were normally distributed for the no counseling group as evidenced by a Shapiro-Wilk's score of W(6) $=.927(p=.557)$ and counseling group with a Shapiro Wilk's score of W(13) $=.974(p=.941)$. In addition, four Q-Q Plots were generated. Figure 5 shows the Q-Q plot of IES-R total scores for no counseling after the ambush; Figure 6 shows the Q-Q plot of IES-R total scores for counseling received after the ambush; Figure 7 shows the Q-Q plot of BRS total scores for no counseling after the ambush; and Figure 8 shows the Q-Q plot of BRS total scores for counseling after the ambush. Each figure shows the approximate normal distribution. Finally, a Levene's test revealed that the assumption of homogeneity of variances was met for the IES-R Total, $F(17)=.044, p=.837$ and the BRS, $F(17)=2.234, p=.153$. 
Figure 5

Q-Q Plot of IES-R Total for No Counseling

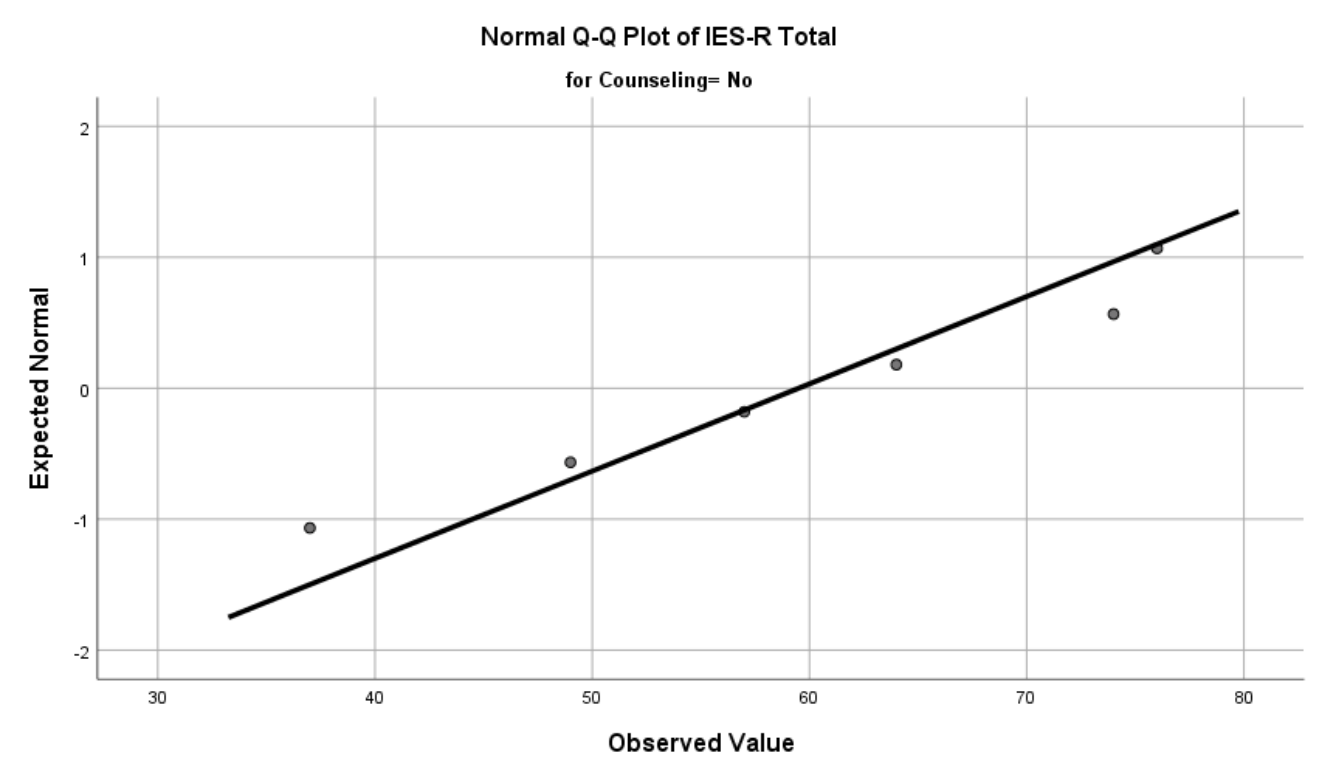

Figure 6

Q-Q Plot of IES-R Total for Counseling

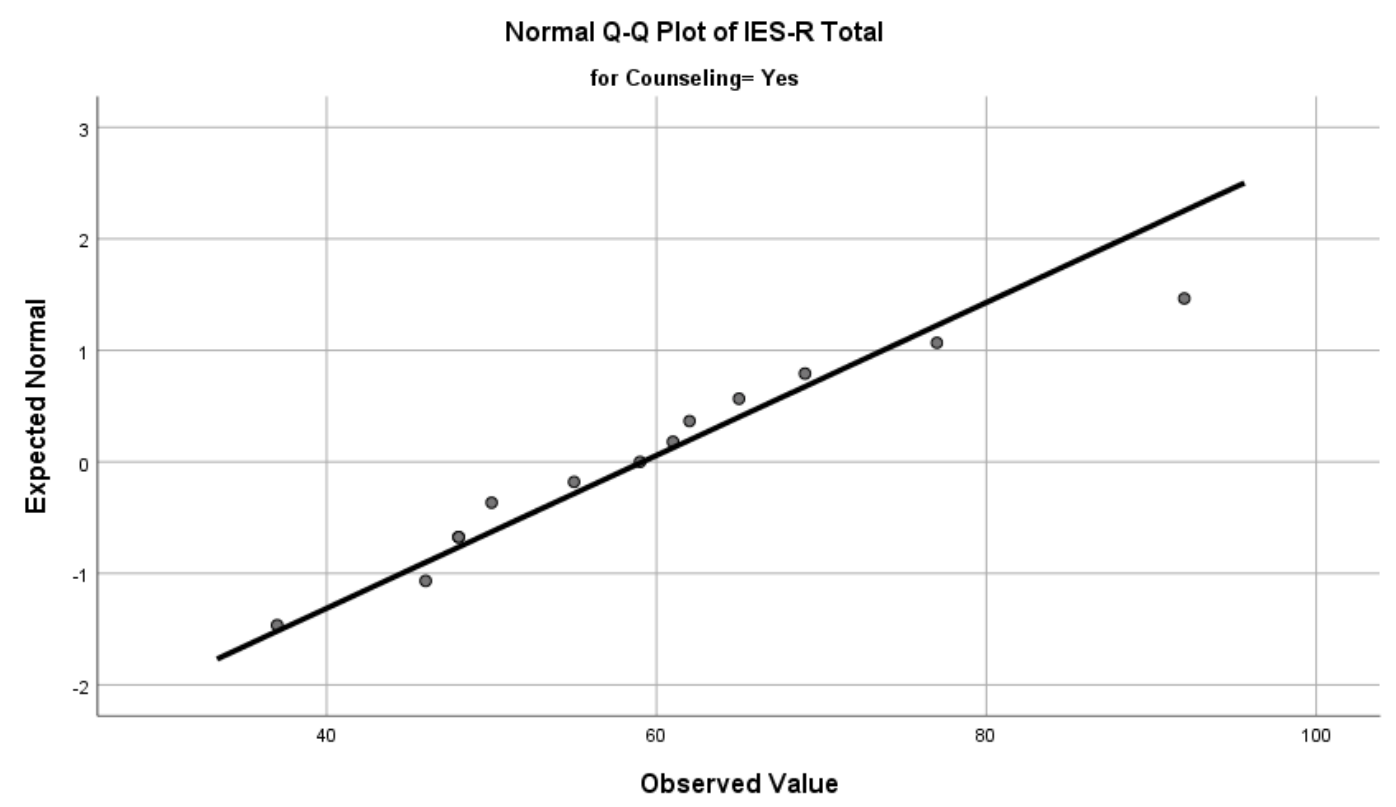


Figure 7

Q-Q Plot of BRS Total for No Counseling

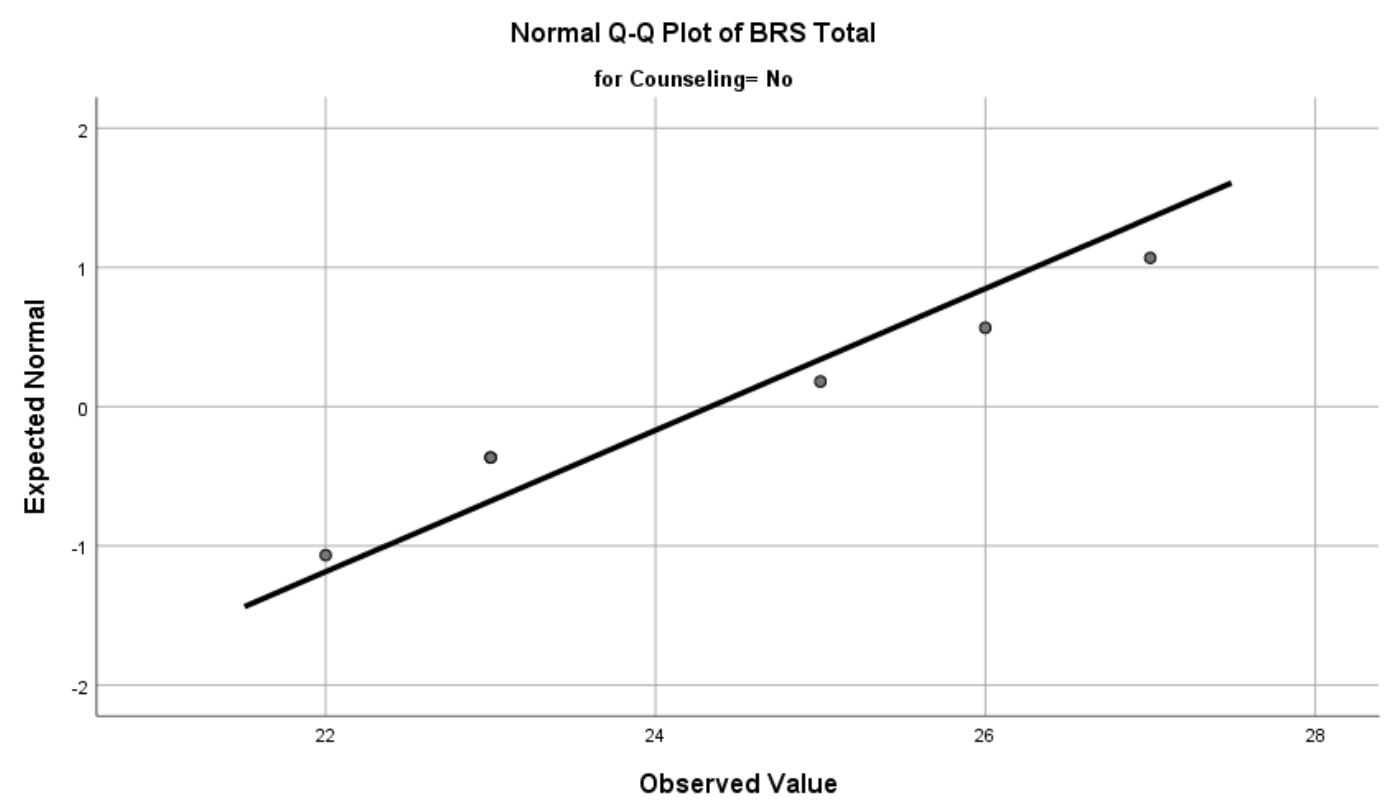

Figure 8

Q-Q Plot of BRS Total for Counseling

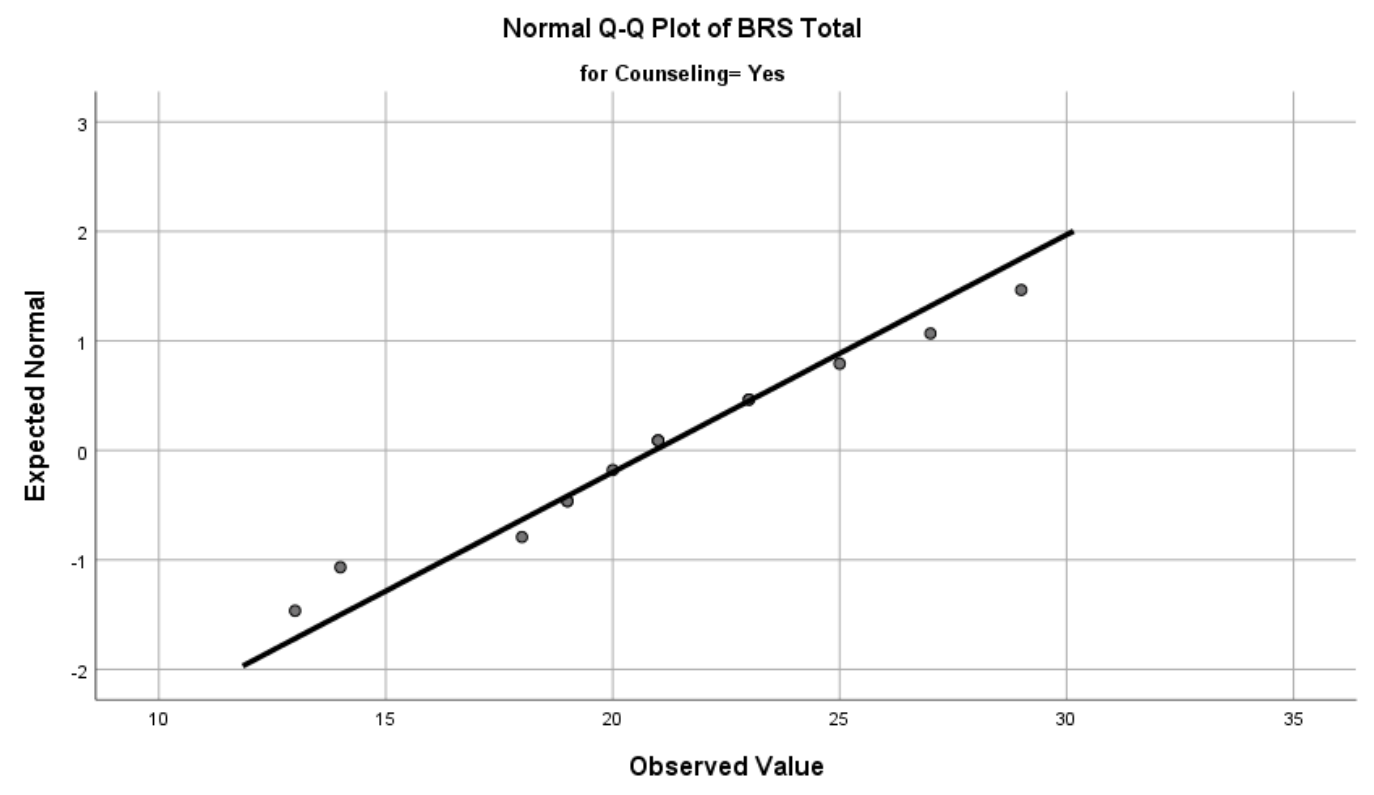




\section{Correlations}

A correlation table of the variables was also generated and is presented in Table 1, below. This table displays a two-tailed probability for each correlation coefficient. This was generated in order to identify any interrelations among the variables of IES-R Total, BRS Total, Gender, Age at Ambush, Years of Experience, Involvement, and Counseling. Table 1 shows that age at the time of the ambush is correlated with years of experience $(r=.843)$.

Since this analysis approached statistical significance at the .10 level, it was decided to rerun the analysis with a random subset of 15 participants. According to the central limit theorem, the mean of a sample will be closer to the mean of the overall population as the sample size increases. This trend was tested to see if with 15 participants the p-value is slightly larger than the p-value of 19 participants. An additional independent samples $t$-test was conducted after randomly choosing 15 of the 19 participants. The results suggested is a trend toward a significant effect $(t(13)=1.41, p=.184)$. Given this trend, with sufficient statistical power (a larger sample size), it is likely that there would be a true statistical effect of those who received counseling reporting lower resilience scores. 
Table 1

Pearson Correlations

\begin{tabular}{|c|c|c|c|c|c|c|c|c|}
\hline & & $\begin{array}{c}\text { IES-R } \\
\text { Total }\end{array}$ & $\begin{array}{l}\text { BRS } \\
\text { Total }\end{array}$ & Gender & $\begin{array}{c}\text { Age at } \\
\text { Ambush }\end{array}$ & $\begin{array}{c}\text { Years of } \\
\text { Experience }\end{array}$ & Involvement & Counseling \\
\hline \multirow[t]{4}{*}{ IES-R Total } & Pearson & 1 & -.104 & .165 & -.048 & -.025 & -.121 & -.012 \\
\hline & Correlation & & & & & & & \\
\hline & Sig. (2-tailed) & & .672 & .500 & .845 & .919 & .621 & .963 \\
\hline & $\mathrm{N}$ & 19 & 19 & 19 & 19 & 19 & 19 & 19 \\
\hline \multirow[t]{4}{*}{ BRS Total } & Pearson & -.104 & 1 & -.115 & -.384 & -.224 & .251 & -.385 \\
\hline & Correlation & & & & & & & \\
\hline & Sig. (2-tailed) & .672 & & .641 & .104 & .356 & .300 & .104 \\
\hline & $\mathrm{N}$ & 19 & 19 & 19 & 19 & 19 & 19 & 19 \\
\hline \multirow[t]{4}{*}{ Gender } & Pearson & .165 & -.115 & 1 & -.007 & -.021 & -.122 & .160 \\
\hline & Correlation & & & & & & & \\
\hline & Sig. (2-tailed) & .500 & .641 & & .978 & .931 & .620 & .513 \\
\hline & $\mathrm{N}$ & 19 & 19 & 19 & 19 & 19 & 19 & 19 \\
\hline Age at & Pearson & -.048 & -.384 & -.007 & 1 & $.894^{* * *}$ & -.328 & .144 \\
\hline \multirow[t]{3}{*}{ Ambush } & Correlation & & & & & & & \\
\hline & Sig. (2-tailed) & .845 & .104 & .978 & & .000 & .171 & .555 \\
\hline & $\mathrm{N}$ & 19 & 19 & 19 & 19 & 19 & 19 & 19 \\
\hline Years of & Pearson & -.025 & -.224 & -.021 & $.894^{* *}$ & 1 & -.289 & .085 \\
\hline \multirow[t]{3}{*}{ Experience } & Correlation & & & & & & & \\
\hline & Sig. (2-tailed) & .919 & .356 & .931 & .000 & & .231 & .729 \\
\hline & $\mathrm{N}$ & 19 & 19 & 19 & 19 & 19 & 19 & 19 \\
\hline \multirow[t]{4}{*}{ Involvement } & Pearson & -.121 & .251 & -.122 & -.328 & -.289 & 1 & .073 \\
\hline & Correlation & & & & & & & \\
\hline & Sig. (2-tailed) & .621 & .300 & .620 & .171 & .231 & & .766 \\
\hline & $\mathrm{N}$ & 19 & 19 & 19 & 19 & 19 & 19 & 19 \\
\hline \multirow[t]{4}{*}{ Counseling } & Pearson & -.012 & -.385 & .160 & .144 & .085 & .073 & 1 \\
\hline & Correlation & & & & & & & \\
\hline & Sig. (2-tailed) & .963 & .104 & .513 & .555 & .729 & .766 & \\
\hline & $\mathrm{N}$ & 19 & 19 & 19 & 19 & 19 & 19 & 19 \\
\hline
\end{tabular}

**. Correlation is significant at the 0.01 level (2-tailed). 


\section{Hypotheses}

Independent samples $t$-tests were conducted to determine whether there were significant differences between victim officers and witness officers based on level of trauma symptomatology, measured by the IES-R (Weiss \& Marmar, 1997) and level of resilience, measured by the BRS) (Smith et al., 2008). The significance level was set to $p=.10$ because this is an exploratory study with a small sample size.

The first hypothesis stated that victim officers will report greater levels of symptomatology than witness officers on the IES-R. Results showed there was not a statistically significant difference in IES-R Total Scores between victim officers and witness officers, $t(17)=$ $.503, p=.621$.

The second hypothesis stated that victim officers would score significantly different on the BRS. There was not a statistically significant difference in BRS Total Scores between victim officers and witness officers, $t(17)=-1.069, p=.300$.

\section{Additional Analyses}

Since this is an exploratory study, additional analyses were computed. An independent samples $t$-test was conducted to determine whether there were significant differences between officers who received counseling and those who did not receive counseling after the ambush, based on level of trauma symptomatology as measured by the IES-R (Weiss \& Marmar, 1997) and level of resilience as measured by the BRS (Smith et al., 2008). The significance level for these analyses was also set to $p=.10$ because this is an exploratory study with a small sample size.

Results showed there was not a statistically significant difference in IES-R Total Scores between officers who received counseling and those who did not receive counseling after the 
ambush, $t(17)=.048, p=.963$. Additionally, there was not a statistically significant difference in BRS Total Scores between officers who received counseling and those who did not receive counseling after the ambush, $t(17)=1.720, p=.104$, although this approached statistical significance. Examination of the mean scores suggests that officers who received counseling scored lower on the BRS than those who did not receive counseling. However, two points must be highlighted: First, the analysis approached statistical significance, but was not significant; second, there was only one witness officer who did not receive counseling. Therefore, the interpretation of a $t$-test, which assesses mean differences, is nonsensical because the score in one cell was based on one individual. 


\section{Chapter 4: Discussion}

The general aim of this study was to examine the differences in symptomatology of trauma and the level of resilience among victim and witness police officers involved in an ambush. The physical danger of police work tends to be emphasized while the psychological danger is often overlooked (Violanti, 2006). Police officers are often exposed to traumatic experiences while at work. A prevalent result of experiencing a traumatic event is posttraumatic stress disorder (Andersen \& Papazoglou, 2016). The traumatic events experienced by police officers can often be life-threatening (McCaslin et al., 2006). One type of life-threatening experience police officers may encounter is an ambush (Crosby \& Lyons, 2016). Studies have been conducted to examine the psychological trauma and resilience experienced by police officers in general, but not specifically officers involved in an ambush. Ellrich and Baier (2015) found that greater stress symptoms were associated with more severe trauma, with more initial reactions showed by police officers. A study conducted by Hartley et al. (2013) found that frequency, recency, and type of traumatic events were associated with PTSD symptoms among police officers. With respect to resilience, Prati and Pietrantoni (2010) found that officers who exhibit lower peritraumatic distress, lower perceived threat, higher self-esteem, and higher social support had the tendency to report less PTSD symptoms. However, there have not been any studies conducted to examine the psychological trauma and resilience of police officers involved in an ambush. Ambushes are important to study because of the high level of personal threat caused by the attack. Traumatic experiences that pose a high level of personal threat, such as being ambushed, are more distressing to police officers than those that do not pose a personal threat (McCaslin et al., 2006). Due to the gap in the research literature, the present study aimed 
to examine symptomatology of trauma and level of resilience experienced by police officers involved in an ambush. Specifically, this study sought to examine those differences with respect to victim officers and witness officers.

Victims and witnesses of traumatic events can both experience posttraumatic reactions (Tierens et al., 2012), although these may differ between victims and witnesses. Witnesses tend to report fewer internalizing symptoms and more externalizing symptoms than victims of a traumatic event. Individuals who experience traumatic events also experience different levels of resilience (Bonanno, 2004). Some individuals who are exposed to a disruptive event may maintain a healthy level of functioning while others recover less quickly. Additionally, GalatzerLevy et al. (2013) found there to be four types of resilience trajectories, including resilient, reactive worsening, chronic distress recovering, and anticipatory distress recovered. Given these considerations, two hypotheses were formed. It was hypothesized that victim police officers would report a greater level of symptomatology on a trauma measure than witness officers. It was also hypothesized that victim and witness officers would score significantly different on a resilience measure.

Initially, four national law enforcement agencies were contacted and asked to assist. One of the agencies requested additional information which was sent, but they never assisted. Additionally, information about the study was posted on Facebook. The one organization that agreed to participate was followed up with after one month and were asked to send the recruitment email through their listserv again. After two months, other law enforcement agencies and organizations were emailed to request assistance in recruiting participants. Those law enforcement agencies and organizations included state agencies, several Fraternal Order of 
Police chapters, and large city police departments. After three months, the survey was closed due to the inability to recruit a sufficient number of participants.

Unfortunately, due to difficulty obtaining participants, the hypotheses and data analyses were changed to explore the data that were gathered. Descriptive statistics were calculated for each of the demographic variables and correlations and independent samples $t$-tests were calculated. Assumptions for the independent $t$-tests were evaluated prior to analysis, and the assumptions were met. The independent samples $t$-tests were used to determine whether there were significant mean differences in the total scores on the Impact of Event Scale - Revised (IES-R; Weiss \& Marmar, 1997) and the Brief Resilience Scale (BRS; Smith et al., 2008) between victim officers and witness officers, as well as individuals who received counseling and those who did not receive counseling after the ambush. The results of these analyses could guide future research. In the following paragraphs, the implications of the analyses that were conducted are presented.

The descriptive statistics for the demographic variables were consistent with the reviewed literature regarding ambushes. A study conducted by the Daniels et al. (2019) regarding ambushes also showed a higher number of male respondents then females. It showed the average age of victim officers was 36.1 years old and witness officers 35.9 years old, which was consistent with the ages of the participants in the current study. Both studies showed that the majority of officers had a bachelor's level of education.

The result showing that age at the time of ambush was correlated with years of experience at the time of ambush was not surprising. It could be assumed that older law enforcement officers have more years of police experience. Examination of the mean scores suggests that witness officers scored lower on the IES-R than victim officers, but not at a 
statistically significant level. The mean scores of victim officers were lower on the BRS than witness officers, but this was also not statistically significant. On the IES-R, the mean scores of officers who received counseling were slightly lower than those who did not receive counseling following the ambush, but this was also not at a statistically significant level. The mean scores of officers who received counseling were lower than those who did not receive counseling following the ambush on the BRS. However, the significance level of officers who received counseling and those who did not receive counseling after the ambush approached a statistically significant level on the BRS but was not.

After completing the additional analyses to test the trend regarding receiving counseling after the ambush and level of resilience, it was found that there may be a true statistical effect of officers who received counseling following an ambush and lower scores on the resilience measure. Therefore, with a larger sample size in a future study, the effect of counseling after an ambush could be examined with respect to level of resilience. If officers who attend counseling have a lower level of resilience, it would be beneficial to determine why that may be the case which could guide future research studies.

An interesting aspect of this study was that four individuals entered the survey but answered "no" to the informed consent and were directed out of the survey. It is possible these individuals did not meet the criteria to answer the survey questions. Alternatively, it is possible that after reading the informed consent, these individuals did not want to answer the questions which are sensitive in nature.

\section{Strengths and Limitations}

The primary strength of this study is that there have not been any other studies that have examined the psychological trauma and resilience of police officers involved in an ambush. 
Previous studies have been limited to psychological trauma and resilience of law enforcement officers in general but have not specifically examined ambushes. The importance of studying psychological trauma and resilience with respect to ambushes is that an ambush poses a personal threat, which can increase the likelihood of posttraumatic stress (McCaslin et al., 2006). Another strength of this study is that it used instruments that are widely used to measure symptomatology of trauma and level of resilience. The IES-R has been shown to be highly correlated with the PTSD Checklist (Weathers, Litz, Herman, Huska, \& Keane 1993) and the BRS has a significant positive correlation with the Connor-Davidson Resilience Scale (Connor \& Davidson, 2003). There are several limitations to this study. Due to the low number of participants, the original data analysis method was unable to be conducted. Therefore, the original hypotheses were unable to be tested. In an effort to gather useful data, the hypotheses were changed, and correlations and independent samples $t$-tests were completed. The major limitation was the difficulty obtaining participants for the study, resulting in low statistical power. There may be a statistical difference in trauma symptomatology and levels of resilience, but it has possible that it is not being detected due to the low statistical power of this study. The current study found that age at the time of the ambush is correlated with years of experience. It also found that there was a not a statistically significant difference in levels of trauma symptomatology and levels of resilience between victims and witnesses after an ambush. However, this could be due to the major limitation of the small sample size of this study. The current study also found that there was not a statistically significant difference between officers who received counseling and those who did not receive counseling after the ambush on levels of trauma symptomatology and levels of resilience. The hope is that this study will encourage additional research on the psychological trauma and resilience of police officers involved in an ambush. Since the difference between 
officers who received counseling and those who did not receive counseling after the ambush approached statistical significance on levels of resilience, a study with a larger sample size may be able to detect an effect if one exists. In the current study, there was only one witness officer who did not receive counseling, which made it difficult to assess mean differences on a group that was based on one individual. Therefore, it would beneficial to conduct these analyses again with a larger sample size.

Many police organizations were contacted in an attempt to obtain assistance with recruitment, a number of which did not respond to the recruitment email. This could be due to several factors. The recruitment email may have been sent to a general email for the organization which is not regularly monitored, the organization may have policies against sending outside emails to their members, or the organization may not have wanted to send out an email regarding a potentially distressing topic. Few organizations agreed to assist with the data collection by forwarding a recruitment email to their members. However, only 46 responses were obtained during the three months of data collection, excluding the individuals that answered "no" on the informed consent. Of those 46 responses, 23 participants answered the items on the IES-R and the BRS but did not respond to the demographics questionnaire, leaving 19 fully completed surveys. It is possible the demographics were not answered due to fear of their anonymity being compromised. One organization asked for additional information to forward to their Office of General Counsel (OGC). It is possible that this organization did not participate because the OGC denied the request due to fear of litigation following the study.

Subject matter experts on the committee remarked that police culture may have had an impact in the low number of participants. Police officers tend to be distrustful of those who are not also members of the law enforcement community. It seems that they believe others might use 
gained information against them. Particularly, with the recent problems between police officers and the general public, they may be hesitant to provide any information regarding ambushes. The officers may have been afraid that the information provided could have made them identifiable. They may also have not seen the benefit of this study to their jobs.

Through the course of this study, it was observed that obtaining participants in the law enforcement community was a difficult task. According to Leishman, Loveday, and Savage (2000), academic research may be viewed by police officers as of little use and the results as being unable to be meaningfully applied. This may have an impact on their willingness to participate in research studies. Loftus (2009) reported that even after being granted access researchers may encounter suspicion and introversion among law enforcement participants. The police officer population is also often close-knit and distrustful of outsiders, which makes it important to obtain formal approval from supervisors (King \& Emma, 2008). It is also important for researchers to gain the trust and cooperation from law enforcement officers to ensure the quality and validity of the data. Hartley et al. (2013) indicated that police officers tend to attempt to conform to cultural norms with regard to mental health because these difficulties are viewed as a weakness. Additionally, Balmer et al. (2014) reported that police officers may underreport symptoms in an attempt to maintain an image of healthy physical and psychological functioning. In order to increase participation in research examining police officers, the researchers should pre-notify officers about the study, obtain assistance from insiders and supervisors, and exclude questions regarding highly sensitive topics (Skogan, Van Craen, \& Hennessy, 2014).

Several reviewed studies were successful in obtaining a large number of participants. A study conducted by McCaslin et al. (2006) assessed whether officers' narratives of their most distressing duty-related incident was related to prediction of greater posttraumatic and 
peritraumatic symptoms. The researchers were able to obtain a sample size of 662 officers. In order to recruit participants, the researchers selected three large urban police departments. The participants were identified by each department's personnel roster. Each potential participant was sent a confidential invitation letter at their home along with letters of support from the head of their department and union leader. The researchers also gave a reimbursement on $\$ 100$ to each participant who returned a completed questionnaire. Weiss et al. (2010) used the same recruiting methods and examined the frequency and severity of exposure to critical incidents as well as the distress caused by these events. They obtained a sample size of 719 officers.

Galatzer-Levy et al. (2013) conducted a longitudinal study to examine the trajectories of resilience and distress among police officer with high exposure to stress. The study followed officers from four urban police department from academy training to 12, 24, 36, and 48 months into active duty. The final sample size of this study was 234 police officers.

Ménard and Arter (2013) were able to obtain a sample size of 750 police officers by using an online questionnaire. They recruited participants through several well-known police organizations such as the International Association of Chiefs of Police and the Fraternal Order of Police and sent information about the survey to sixty-five police associations in the six most populous states in the United States. They also recruited additional participants by sending the information to 35 police officers and agencies in Canada and the United States who were known to the authors. These officers were informed that the survey was online, confidential, anonymous, and approved by Penn State University's Institutional Review Board. This study examined the relationships among critical incidents, negative coping skills, social stressors, problematic alcohol use, and posttraumatic symptoms after controlling for police officer demographics. 
Another limitation of this study is that the ambushes being studied occurred at different times. Due to the time difference of these ambushes, it is possible that the resilience and trauma levels of these individuals have changed over time. The officers who experienced an ambush that occurred many years ago may have lower traumatic stress symptoms than an officer who experienced an ambush more recently. Prati and Pietrantoni (2010) and McCanlies et al. (2014) noted that recall bias may have an impact on the symptoms reported on questionnaires. This study attempted to used time since the attack as a covariate; however, due to the limited sample size, it was unable to be examined.

\section{Future Directions}

This study can guide future research on psychological trauma and resilience of police officers involved in an ambush. Future studies could replicate this study using better ways to recruit participants in an effort to obtain the minimum number of participants needed to conduct the ANCOVA to test the hypotheses, as well as a larger size when conducting an independent samples $t$-test. It may be helpful to expand the research study to participants in other highly populated geographic areas to increase the number of officers reached by the recruitment letter. As previously discussed, a study by Nix, Pickett, Baek, and Alpert (2017) reported that in-person surveys have higher response rates than those conducted online, over the telephone, and general mail. It also showed that incentives increase response rates in all modes. It may be beneficial for researchers to conduct future surveys in person with a higher incentive than was offered for this study. To recruit additional participants in the future, it may be beneficial to gain support from the leader of each police organization, such as a chief. With the support from the leaders, it may be easier to gather additional participants if the request comes from a supervisor in the organization. Additionally, future studies can expand upon this research by replicating it with a 
larger sample. Future research could also be used to guide the psychological treatment of officers involved in an ambush. The exploration of these areas could assist with interventions and contribute to the literature regarding psychological trauma and resilience. It would be helpful to study the types of interventions that are effective for police officers involved in an ambush. Additionally, further research regarding increasing levels of resilience would be helpful to lessen the psychological impact of ambushes on victim and witness officers.

As previously discussed, with a larger sample size there would likely be a true statistical effect that officers who received counseling after an ambush would have lower resilience scores. Future studies could further explore this trend with a larger sample size. It is possible that officers were required by their department to receive counseling following an ambush. This could have an impact on resilience because of possible unwillingness to participate in therapy sessions if they were required to attend them. Specific officers may have been required to participate in counseling because it was believed they were having a difficult time or were involved in additional traumatic events. It would be beneficial to ask about a counseling requirement in the demographics questionnaire. Additionally, it is possible that these officers had a lower level of resilience prior to the ambush. Officers with less social support from friends and family, the community, and their departments may have had lower resilience before being involved in a traumatic event, such as an ambush. Lower social support is often associated with lower levels of resilience. It may be that those who did not receive counseling had greater resilience prior to the ambush, and/or received greater social supports following the attack than those who sought counseling. 


\section{Conclusions}

The present study was an exploratory study regarding trauma symptomatology and levels of resilience among LEOs who either witnessed or were victims of ambushes. There was a statistically significant correlation between age at the time of ambush and years of experience at the time of ambush, which is not surprising. The independent samples $t$-tests showed that there were no statistically significant differences between victims and witnesses of ambushes on trauma symptomatology and level of resilience. Similarly, an additional independent samples $t$ test showed that there was also not a statistically significant difference between officers who received counseling and officers who did not receive counseling after an ambush on trauma symptomatology and level of resilience. Future research should attempt to find better ways to recruit law enforcement participants as well as study the impact of ambushes on police officers. 


\section{References}

American Psychiatric Association. (2013). Diagnostic and statistical manual of mental disorders (5th ed.). Washington, DC: American Psychiatric Association.

Andersen, J. P., \& Papazoglou, K. (2016). Police Health Professionals' Knowledge and Practices in Educating Officers about Trauma and Health. Journal of Law Enforcement, 5(5), 1-21. doi: $10.1177 / 2158244015580380$

Balmer, G. M., Pooley, J. A., \& Cohen, L. (2014). Psychological resilience of Western Australian police officers: relationship between resilience, coping style, psychological functioning, and demographics. Police Practice \& Research, 15(4), 270-282. doi:10.1080/15614263.2013.845938

Bonanno, G. A. (2004). Loss, trauma, and human resilience: Have we underestimated the human capacity to thrive after extremely aversive events? American Psychologist, 59(1), 20. doi:10.1037/0003-066X.59.1.20

Bonanno, G. A., \& Mancini, A. D. (2012). Beyond resilience and PTSD: Mapping the heterogeneity of responses to potential trauma. Psychological Trauma: Theory, Research, Practice, and Policy, 4(1), 74. doi:10.1037/a0017829

Block, J., \& Kremen, A. M. (1996). IQ and ego-resiliency: Conceptual and empirical connections and separateness. Journal of Personality and Social Psychology, 70, 349361. doi:10.1037/0022-3514.70.2.349

Burke, K. J., \& Shakespeare-Finch, J. (2011). Markers of resilience in new police officers: Appraisal of potentially traumatizing events. Traumatology, 17(4), 52-60. doi:10.1177/1534765611430725 
Connor, K. M., \& Davidson, J. R. T. (2003). Development of a new resilience scale: The Connor-Davidson Resilience Scale (CD-RISC). Depression and Anxiety, 18, 76-82. doi:10.1002/da.10113

Creamer, M., Bell, R., \& Failla, S. (2003). Psychometric properties of the Impact of Event Scale Revised. Behaviour Research and Therapy, 41(12), 1489-1496. doi:10.1016/j.brat.2003.07.010

Crosby A. E., \& Lyons, B. (2016). Assessing homicides by and of US law-enforcement officers. New England Journal of Medicine, 375 (16), 1509-1511. doi:0.1056/NEJMp1609905

Daniels, J. A., Sheets, J., Wright, P. \& McAllister, B. (2019). Ambushes and unprovoked attacks: Assaults on our nation's law enforcement officers. Washington, DC: US Department of Justice.

De Groot, A. \& Fachner G. (2014). Protecting Officers from Ambush Attacks: Key Insights from Law Enforcement Executives. Officer Safety Corner, The Police Chief, 81, 10-11.

Ellrich, K., \& Baier, D. (2015). Post-Traumatic Stress Symptoms in Police Officers Following Violent Assaults: A Study on General and Police-Specific Risk and Protective Factors. Journal of Interpersonal Violence, 1-26. doi:10.1177/0886260515586358

Fachner, G., \& Thorkildsen, Z. (2015). Ambushes of Police: Environment, Incident Dynamics, and the Aftermath of Surprise Attacks Against Law Enforcement. Washington, D.C.: Office of Community Oriented Policing Services.

Faul, F., Erdfelder, E., Lang, A. G., \& Buchner, A. (2007). G*Power 3: A flexible statistical power analysis program for the social, behavioral, and biomedical sciences. Behavior Research Methods, 39, 175-191. 
Field, A. P. (2009). Discovering statistics using SPSS (and sex and drugs and rock' n' roll) (3rd Ed.). London: Sage.

Galatzer-Levy, I. R., Brown, A. D., Henn-Haase, C., Metzler, T. J., Neylan, T. C., \& Marmar, C. R. (2013). Positive and negative emotion prospectively predict trajectories of resilience and distress among high-exposure police officers. Emotion, 13(3), 545-553. doi:10.1037/a0031314

Hartley, T. A., Sarkisian, K., Violanti, J. M., Andrew, M. E., \& Burchfiel, C. M. (2013). PTSD symptoms among police officers: associations with frequency, recency, and types of traumatic events. International Journal of Emergency Mental Health, 15(4), 241.

Hartley, T. A., Violanti, J. M., Mnatsakanova, A., Andrew, M. E., \& Burchfiel, C. M. (2013). Military Experience and Levels of Stress and Coping in Police Officers. International Journal of Emergency Mental Health, 15(4), 229-239.

Heppner, P. P., Wampold, B. E., \& Kivlighan, D. M. (2008). Quantitative descriptive research designs. In, Research Design in Counseling. Belmont, CA: Thomson Brooks/Cole.

IBM Corp. Released 2013. IBM SPSS Statistics for Windows, Version 22.0. Armonk, NY: IBM Corp.

International Association of Chiefs of Police (IACP). (2014). Ambush fact sheet. Retrieved from www.theiacp.org/Ambush-project.

Janson, G. R., Carney, J. V., Hazier, R. J., \& Insoo, O. (2009). Bystanders' Reactions to Witnessing Repetitive Abuse Experiences. Journal of Counseling \& Development, 87(3), 319-326. doi: 10.1002/j.1556-6678.2009.tb00113.x

Jones, E., \& Wessely, S. (2006). Psychological trauma: A historical perspective. Psychiatry, 5, 217-220. doi:10.1053/j.mppsy.2006.04.011 
King, R. \& Emma, W. (2008). Doing Research on Crime and Justice. Oxford: Oxford University Press, 343-362.

Leigh Wills, J., \& Schuldberg, D. (2016). Chronic Trauma Effects on Personality Traits in Police Officers. Journal of Traumatic Stress, 29(2), 185-189. https://doiorg.www.libproxy.wvu.edu/10.1002/jts.22089

Leishman, F., Loveday, B., \& Savage, S. (2000). Core issues in policing. Longman Group.

Loftus, B., 2009. Police culture in a changing world. Oxford: Oxford University Press.

Ménard, K. S., \& Arter, M. L. (2013). Police officer alcohol use and trauma symptoms: Associations with critical incidents, coping, and social stressors. International Journal of Stress Management, 20(1), 37-56. doi:10.1037/a0031434

McCanlies, E. C., Mnatsakanova, A., Andrew, M. E., Burchfiel, C. M., \& Violanti, J. M. (2014). Positive Psychological Factors are Associated with Lower PTSD Symptoms among Police Officers: Post Hurricane Katrina. Stress \& Health: Journal of the International Society for the Investigation of Stress, 30(5), 405-415. doi:10.1002/smi.2615

McCaslin, S. E., Rogers, C. E., Metzler, T. J., Best, S. R., Weiss, D. S., Fagan, J. A., Liberman, A., \& Marmar, C. R. (2006). The impact of personal threat on police officers' responses to critical incident stressors. The Journal of Nervous and Mental Disease, 194(8), 591597. doi:10.1097/01.nmd.0000230641.43013.68

McCraty, R., \& Atkinson, M. (2012). Resilience Training Program Reduces Physiological and Psychological Stress in Police Officers. Global Advances in Health and Medicine: Improving Healthcare Outcomes Worldwide, 1(5), 44-66. doi:10.7453/gahmj.2012.1.5.013 
Nix, J., Pickett, J.T., Baek, H., \& Alpert, G.P. (2017). Police research, officer surveys, and response rates. Policing and Society. doi:10.1080/10439463.2017.1394300

Papazoglou, K., \& Andersen, J. P. (2014). A guide to utilizing police training as a tool to promote resilience and improve health outcomes among police officers. Traumatology: An International Journal, 20(2), 103-111. doi:10.1037/h0099394

Patterson, G. T. (2001). The relationship between demographic variables and exposure to traumatic incidents among police officers. The Australian Journal of Disaster and Trauma Studies, 2001-2.

Pietrzak, R. H., Feder, A., Singh, R., Schechter, C. B., Bromet, E. J., Katz, C. L., \& Southwick, S. M. (2014). Trajectories of PTSD risk and resilience in World Trade Center responders: an 8-year prospective cohort study. Psychological Medicine, 44(1), 205-219. doi:10.1017/S0033291713000597

Prati, G., \& Pietrantoni, L. (2010). Risk and resilience factors among Italian municipal police officers exposed to critical incidents. Journal of Police and Criminal Psychology, 25(1), 27-33. doi:10.1007/s11896-009-9052-0

Qualtrics: Online Survey Software \& Insight Platform. (2009). Retrieved November 14, 2014, from http://www.qualtrics.com/

Rice, V., \& Liu, B. (2016). Personal resilience and coping Part II: Identifying resilience and coping among U.S. military service members and veterans with implications for work. Work, 54(2), 335-350. https://doi-org.www.libproxy.wvu.edu/10.3233/WOR-162301

Ryff, C. D., \& Keyes, C. L. M. (1995). The structure of psychological well-being revisited. Journal of Personality and Social Psychology, 69, 719-727. doi:10.1037/00223514.69.4.719 
Salkind, N. J. (2011). Statistics for people who (think they) hate statistics (4th ed.). Thousand Oaks, CA: SAGE Publications.

Scheier, M. F., Carver, C. S., \& Bridges, M. W. (1994). Distinguishing optimism from neuroticism (and trait anxiety, self-mastery, and self-esteem): A reevaluation of the Life Orientation Test. Journal of Personality and Social Psychology, 67, 1063- 1078. doi:10.1037//0022-3514.67.6.1063

Schouten, R., \& Brennan, D. V. (2016). Targeted violence against law enforcement officers. Behavioral Sciences \& The Law, 34(5), 608-621. doi:10.1002/bsl.2256

Skogan, W. G., Van Craen, M., \& Hennessy, C. (2014). Training Police for Procedural Justice. Journal of Experimental Criminology. doi: 10.1007/s11292-014-9223-6

Smith, B. W., Epstein, E. M., Ortiz, J., Christopher, P. J., \& Tooley, E. M. (2013). The foundations of resilience: What are the critical resources for bouncing back from stress? In S. Prince-Embury \& D. H. Saklofske (Eds.), Resilience in children, adolescents, and adults: Translating research into practice (pp. 167-187). New York: Springer.

Smith, B.W., Dalen, J., Wiggins, K., Tooley, E., Christopher, P., \& Bernard, J. (2008). The Brief Resilience Scale: Assessing the ability to bounce back. The International Journal of Behavioral Medicine, 15, 194-200. doi:10.1080/10705500802222972

Smith, B. W., Tooley, E. M., Christopher, P. J., \& Kay, V. S. (2010). Resilience as the ability to bounce back from stress: a neglected personal resource? The Journal of Positive Psychology, 5, 166- 176. doi:10.1080/17439760.2010.482186

Tierens, M., Bal, S., Crombez, G., Loeys, T., Antrop, I., \& Deboutte, D. (2012). Differences in posttraumatic stress reactions between witnesses and direct victims of motor vehicle accidents. Journal of Traumatic Stress, 25(3), 280-287. doi:10.1002/jts.21692 
United States Department of Justice, Federal Bureau of Investigation. (1992). Killed in the Line of Duty: A Study of Selected Felonious Killings of Law Enforcement Officers. Washington, DC: U.S. Department of Justice.

United States Department of Justice, Federal Bureau of Investigation. (1997). In the Line of Fire: Violence Against Law Enforcement. Washington, DC: U.S. Department of Justice.

United States Department of Justice, Federal Bureau of Investigation. (2006). Violent Encounters: A Study of Felonious Assaults on Our Nation's Law Enforcement Officers. Washington, DC: U.S. Department of Justice.

United States Department of Justice, Federal Bureau of Investigation. (September 2012). Law Enforcement Officers Killed and Assaulted, 2016. Retrieved (2018, January 8), from https://ucr.fbi.gov/leoka/2016.

Weathers, F. W., Litz, B. T., Herman, D. S., Huska, J. A., \& Keane, T. M. (1993). The PTSD Checklist (PCL): reliability, validity, and diagnostic utility. Paper presented at the 9th annual conference of the ISTSS, San Antonio.

Weltman, G., Lamon, J., Freedy, E., \& Chartrand, D. (2014). Police department personnel stress resilience training: an institutional case study. Global Advances in Health and Medicine: Improving Healthcare Outcomes Worldwide, 3(2), 72-79. doi:10.7453/gahmj.2014.015

Weiss, D. S., Brunet, A., Best, S. R., Metzler, T. J., Liberman, A., Pole, N., Fagan, J., Marmar, C. R. (2010). Frequency and severity approaches to indexing exposure to trauma: The Critical Incident History Questionnaire for police officers. Journal of Traumatic Stress, 23, $734-743$. doi:10.1002/jts.20576 
Weiss, D.S.; Marmar, C.R. (1997). The impact of event scale - revised. In: Wilson, JP.; Keane, TM., editors. Assessing psychological trauma and PTSD. New York: Guilford Press; p. $399-411$.

Violanti, J. M. (2006). The police: Perspectives on trauma and resiliency. Traumatology, 12(3), 167-169. doi:10.1177/1534765606296998

Young, T. J. (1990). Felonious murder of police officers by ambush. Psychological reports, 67(1), 206-206. 


\section{APPENDIX A \\ IMPACT OF EVENT SCALE - REVISED}

INSTRUCTIONS: Below is a list of difficulties people sometimes have after stressful life events. Please read each item, and then indicate how distressing each was for you AT THE TIME OF THE AMBUSH, which occurred on (date of ambush). How much were you distressed or bothered by these difficulties?

Any reminder brought back feelings about it.
Not at all
A little bit
Moderately
Quite a bit
Extremely
0
1
2
3
4

I had trouble staying asleep.
Not at all
A little bit
Moderately
Quite a bit
Extremely
0 1
2
3
4

Other things kept making me think about it.
Not at all
A little bit
Moderately
Quite a bit
Extremely
2
3
4

0

I felt irritable and angry.
Not at all
A little bit
Moderately
Quite a bit
Extremely
0 1 2 3 4

I avoided letting myself get upset when I thought about it or was reminded of it.
Not at all
A little bit
Moderately
Quite a bit
Extremely
0
1
2
3
4

I thought about it when I didn't mean to.
Not at all
A little bit
Moderately
Quite a bit
Extremely
0
1
2
3
4

I felt as if it hadn't happened or wasn't real.
Not at all
A little bit
Moderately
Quite a bit
Extremely
0
1
2
3
4

I stayed away from reminders of it.
Not at all
A little bit
Moderately
Quite a bit
Extremely
0
1
2
3
4

Pictures about it popped into my mind.
Not at all
A little bit
Moderately
Quite a bit
Extremely
0 
I was jumpy and easily startled.

$\begin{array}{ccccc}\text { Not at all } & \text { A little bit } & \text { Moderately } & \text { Quite a bit } & \text { Extremely } \\ 0 & 1 & 2 & 3 & 4\end{array}$

I tried not to think about it.

Not at all

A little bit

Moderately

Quite a bit

Extremely

0

1

2

3

4

I was aware that I still had a lot of feelings about it, but I didn't want to deal with them.

Not at all

A little bit

Moderately

Quite a bit

Extremely

0

1

2

3

4

My feelings about it were kind of numb.
Not at all
A little bit
Moderately
Quite a bit
Extremely

0

1

2

3

4

I found myself acting or feeling like I was back at that time.
Not at all
A little bit
Moderately
Quite a bit
Extremely
0
1
2
3
4

I had trouble falling asleep.
Not at all
A little bit
Moderately
Quite a bit
Extremely
0
1
2
3
4

I had waves of strong feelings about it.
Not at all
A little bit
Moderately
Quite a bit
Extremely
0

1

2

3

4

I tried to remove it from my memory.

Not at all

0
A little bit

1
Moderately

2
Quite a bit

3
Extremely

4

I had trouble concentrating.

Not at all

0

A little bit
Moderately

2
Quite a bit 3
Extremely 4

Reminders of it caused me to have physical reactions, such as sweating, trouble breathing, nausea, or a pounding heart.

Not at all

0

A little bit

1

I had dreams about it.

Not at all

0
A little bit

1
Moderately

2

Moderately

2
Quite a bit

3

Quite a bit

3
Extremely

4

Extremely

4 
I felt watchful and on-guard.

Not at all

0

(1)

to

I tried not to talk about it.

Not at all

A little bit

0

1
Moderately

2

Moderately

2
Quite a bit

3

Quite a bit

3
Extremely

4

Extremely

4 


\section{APPENDIX B \\ BRIEF RESILIENCE SCALE}

INSTRUCTIONS: Use the following scale and select one number for each statement to indicate how much you disagree or agree with each of the statements.

I tend to bounce back quickly after hard times.

Strongly Disagree $\quad$ Disagree $\quad$ Neutral $\quad$ Agree $\quad$ Strongly Agree

$\begin{array}{lllll}1 & 3 & 4 & 5\end{array}$

I have a hard time making it through stressful events.

$\begin{array}{ccccc}\text { Strongly Disagree } & \text { Disagree } & \text { Neutral } & \text { Agree } & \text { Strongly Agree } \\ 1 & 2 & 3 & 4 & 5\end{array}$

It does not take me long to recover from a stressful event.

$\begin{array}{ccccc}\text { Strongly Disagree } & \text { Disagree } & \text { Neutral } & \text { Agree } & \text { Strongly Agree } \\ 1 & 2 & 3 & 4 & 5\end{array}$

It is hard for me to snap back when sometime bad happens.

$\begin{array}{llll}\text { Strongly Disagree } & \text { Disagree } & \text { Neutral } & \text { Agree }\end{array}$

$1203 \quad 4 \quad 5$

I usually come through difficult times with little trouble.

$\begin{array}{ccccc}\text { Strongly Disagree } & \text { Disagree } & \text { Neutral } & \text { Agree } & \text { Strongly Agree } \\ 1 & 2 & 3 & 4 & 5\end{array}$

I tend to take a long time to get over set-backs in my life.

$\begin{array}{llll}\text { Strongly Disagree } & \text { Disagree } & \text { Neutral } & \text { Agree }\end{array}$ 


\section{APPENDIX C}

\section{DEMOGRPAHICS DATA FORM}

Please complete the following information.

\begin{tabular}{|c|c|c|}
\hline TEXT & ANSWERS & TYPE \\
\hline Gender: & $\begin{array}{ll}\circ & \text { Male } \\
\circ & \text { Female } \\
\circ & \text { Other: } \\
\end{array}$ & Multiple Choice \\
\hline Age at Time of Ambush: & 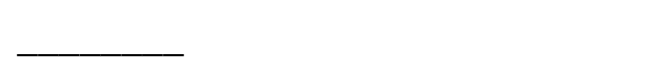 & Text Entry \\
\hline What is your race/ethnicity? & $\begin{array}{ll}\circ & \text { American Indian or Alaska Native } \\
\circ & \text { Asian American/Asian } \\
\circ & \text { Black/African American } \\
\circ & \text { Hispanic/Latino/a } \\
\circ & \text { Multiracial } \\
\circ & \text { Native Hawaiian/Pacific Islander } \\
\circ & \text { White/Caucasian } \\
\circ & \text { Other: }\end{array}$ & Multiple Choice \\
\hline Level of Education: & $\begin{array}{ll}\circ & \text { GED } \\
\circ & \text { High school diploma } \\
\circ & \text { Associate's Degree } \\
\circ & \text { Bachelor's Degree } \\
\circ & \text { Master's Degree } \\
\circ & \text { Doctoral Degree } \\
\circ & \text { Other: } \\
\end{array}$ & Multiple Choice \\
\hline Work Status: & $\begin{array}{ll}\circ & \text { Part-time } \\
\circ & \text { Full-time } \\
\circ & \text { Retired } \\
\circ & \text { Other (specify): } \\
\end{array}$ & Multiple Choice \\
\hline
\end{tabular}




\begin{tabular}{|c|c|c|}
\hline Type of agency: & $\begin{array}{ll}\circ & \text { City } \\
\circ & \text { County } \\
\circ & \text { Federal } \\
\circ & \text { Tribal (non-federal only) } \\
\circ & \text { State } \\
\circ & \text { Other (specify): } \\
& \end{array}$ & Multiple Choice \\
\hline Rank in Agency: & & Text Entry \\
\hline $\begin{array}{l}\text { Years of Police Experience at } \\
\text { Time of the Ambush: }\end{array}$ & & Text Entry \\
\hline Date of Ambush: & $\longrightarrow$ & Text Entry \\
\hline Type of Assignment: & $\begin{array}{ll} & \text { One-officer patrol } \\
\circ & \text { Two-officer patrol } \\
\circ & \text { Investigative/detection } \\
\circ & \text { Tactical assignment (uniformed) } \\
\circ & \text { Plainclothes assignment } \\
\circ & \text { Special assignment (specify): } \\
\circ & \text { Undercover } \\
\circ & \text { Court/prisoner security } \\
\circ & \text { Overtime/extra duty activity } \\
\circ & \text { Off duty, but acting in an official } \\
& \text { capacity } \\
\circ & \text { Other (specify): } \\
\end{array}$ & Multiple Choice \\
\hline Involvement in Ambush: & $\begin{array}{ll}\circ & \text { Victim } \\
\circ & \text { Witness }\end{array}$ & Multiple Choice \\
\hline Status of Victim Officer: & $\begin{array}{ll}\circ & \text { Deceased } \\
\circ & \text { Retired } \\
\circ & \text { Returned to duty }\end{array}$ & Multiple Choice \\
\hline
\end{tabular}




\begin{tabular}{|c|c|c|}
\hline $\begin{array}{l}\text { Type of Weapon Used by } \\
\text { Offender: }\end{array}$ & $\begin{array}{ll}\circ & \text { Firearm } \\
\circ & \text { Knife } \\
\circ & \text { Other Cutting Instrument (Specify): } \\
\circ & \text { Bomb } \\
\circ & \text { Blunt Instrument } \\
\circ & \text { Personal weapons (hands, fists, feet, } \\
& \text { etc.) } \\
\circ & \text { Vehicle } \\
\circ & \text { Other (Specify): }\end{array}$ & Multiple Choice \\
\hline $\begin{array}{l}\text { Did you receive counseling after } \\
\text { the ambush?: }\end{array}$ & $\begin{array}{ll}\circ & \text { Yes } \\
\circ & \text { No }\end{array}$ & Multiple Choice \\
\hline
\end{tabular}

Please provide an email address if you would like to be entered into a drawing to win one of four $\$ 25$ Visa electronic gift cards:

Winners of the drawing will be notified after the study has closed. Your email address will not be associated with your survey responses. Additionally, participation or refusal to participate in this drawing will not impact inclusion in this study. 


\section{APPENDIX D}

\section{EMAIL TO PUBLICATIONS}

To Whom It May Concern:

My name is Erin Teaff, and I am a doctoral candidate in Counseling Psychology from West Virginia University. Additionally, I am currently an intern at the Federal Bureau of Investigation.

I am in the process of writing my proposal for my dissertation. The purpose of the study is to examine the psychological trauma and resilience of victim and witness police officers involved in an ambush. This research will likely benefit future officers involved in ambushes, as well as guide future research on the trauma and resilience experienced by officers involved in ambushes. Additionally, this research will likely assist in improving the psychological treatment of officers who have been involved in an ambush.

I would like permission to send a recruitment email on your listserv to members of your organization pending approval of my dissertation prospectus. I would be sending the email out around mid-August. I am contacting you now because WVU's Institutional Review Board will be requesting a list of organizations that will allow me to recruit participants. Thank you for your consideration. I look forward to hearing from you.

Thanks again,

Erin

Erin A. Teaff, M.S. CRC

Doctoral Candidate in Counseling Psychology

West Virginia University

502 Allen Hall

Eteaff@mix.wvu.edu 


\section{APPENDIX E}

\section{ADDITIONAL INFORMATION LETTER}

To Whom It May Concern:

My name is Erin Teaff, and I am a doctoral candidate in Counseling Psychology at West Virginia University (WVU). Additionally, I am currently an intern at the Federal Bureau of Investigation. I am in the process of writing my proposal for my dissertation. The purpose of the study is to examine the psychological trauma and resilience of victim and witness police officers involved in an ambush.

I would like for you to send a recruitment email on your listserv to members of your organization on my behalf pending approval of my dissertation prospectus. I am contacting you now because WVU's Institutional Review Board will be requesting a list of organizations that will assist me in recruiting participants.

This study is designed to examine the differences in psychological trauma and resilience between victim officers and witness officers involved in an ambush. The requirements to participate in this study are as follows:

- You must be 18 years of age or older

- You must be a current or past sworn law enforcement officers in the United States. Specifically, you will have been employed as a sworn law enforcement officer within a city, university or college, county, state, tribal, or federal agency during the time of the ambush.

- You must meet the following criteria: wore or carried a badge, carried a firearm, was duly sworn and had full arrest powers, was a member of a public governmental law enforcement agency and was paid from government funds set aside specifically for payment to sworn law enforcement, and was acting in an official capacity, whether on or off duty, at the time of the ambush.

- You must have been a victim or witness of the ambush. A victim officer is an officer who was injured as a result of the ambush. A witness officer is an officer who witnessed another officer being killed or injured, but were not injured themselves, during an ambush.

Participants will be asked to respond to statements related to distress and resilience experienced as a result of an ambush. These statements are comprised of two psychological instruments, the Brief Resilience Scale and the Impact of Event Scale-Revised. Additionally, participants will be asked to answer several demographic questions. These statements and questions will be presented as an online questionnaire and will take approximately 10 minutes to complete.

I will not ask any information that should lead back to an individual's identity as a participant. Participation is completely voluntary, and participants may skip any question that they do not wish to answer, and they may discontinue at any time. Participants will not be affected if they 
decide either not to participate or to withdraw. At the completion of the questionnaire, participants will be provided with a list of mental health resources in case they experience discomfort when answering questions related to a previous traumatic event. Additionally, participants have the option to enter into a drawing for one of four \$25 Visa gift cards.

This research will likely benefit future officers involved in ambushes, as well as guide future research on the trauma and resilience experienced by officers involved in ambushes.

Additionally, this research will likely assist in improving the psychological treatment of officers who have been involved in an ambush.

Thank you for your consideration. I look forward to hearing from you.

Sincerely,

Erin

Erin A. Teaff, M.S. CRC

Doctoral Candidate in Counseling Psychology

West Virginia University

502 Allen Hall

Eteaff@mix.wvu.edu 


\section{APPENDIX F}

\section{LETTER TO PARTICIPANTS}

\section{Dear Participant,}

This letter is a request for you to take part in a research study at West Virginia University (WVU) on psychological trauma and resilience of police officers involved in an ambush. This project is being conducted by Erin A. Teaff, M.S. in the Department of Counseling, Rehabilitation Counseling, and Counseling at WVU with supervision of Dr. Jeffrey Daniels, Department Chairperson and Professor. Your participation in this project is greatly appreciated and will take approximately 10 minutes to fill out an online survey. You can access the survey at

Your involvement in this project will be kept as confidential as legally possible as no identifying information will be collected. The requirements to participate in this study are as follows:

- You must be 18 years of age or older

- You must be a current or past sworn law enforcement officers in the United States. Specifically, you will have been employed as a sworn law enforcement officer within a city, university or college, county, state, tribal, or federal agency during the time of the ambush.

- You must meet the following criteria: wore or carried a badge, carried a firearm, was duly sworn and had full arrest powers, was a member of a public governmental law enforcement agency and was paid from government funds set aside specifically for payment to sworn law enforcement, and was acting in an official capacity, whether on or off duty, at the time of the ambush.

- You must have been a victim or witness of the ambush. A victim officer is an officer who was injured as a result of the ambush. A witness officer is an officer who witnessed another officer being killed or injured, but were not injured themselves, during an ambush.

I will not ask any information that should lead back to your identity as a participant. Your participation is completely voluntary. You may skip any question that you do not wish to answer, and you may discontinue at any time. You will not be affected if you decide either not to participate or to withdraw. At the completion of the questionnaire, you will have the option to enter into a drawing for one of four \$25 Visa gift cards.

I hope that you will participate in this research project, as it could be beneficial in understanding the psychological impact of an ambush on police officers. Thank you very much for your time. Should you have any questions about this letter or the research project, please feel free to contact Erin Teaff at eteaff@mix.wvu.edu or Dr. Daniels at Jeffrey.Daniels@mail.wvu.edu.

Additionally, if you know of any individual who may meet the requirements to participate in this study, please forward this email to them. 
Thank you for your time and help with this project.

Sincerely,

Erin A. Teaff, M.S.

Counseling Psychology Doctoral Candidate

Department of Counseling, Rehabilitation Counseling, and Counseling Psychology

West Virginia University 


\section{APPENDIX G}

\section{INFORMED CONSENT}

\section{Only Minimal Risk}

Consent Information Form (without HIPAA)

Principal Investigator

Department

Protocol Number

Study Title

\section{Involved in an Ambush}

Co-Investigator(s)
Jeffrey Daniels, Ph.D.

Counseling, Rehabilitation Counseling, \& Counseling Psychology

Click here to enter text.

Psychological Trauma and Resilience of Police Officers

\section{Contact Persons}

In the event you experience any side effects or injury related to this research, you should contact Jeffrey Daniels, Ph.D. during business hours at (304) 293-2235 or Jeffrey.Daniels@mail.wvu.edu. If you have any questions, concerns, or complaints about this research, you can contact Dr. Daniels. Alternatively, you can contact Erin A. Teaff, M.S. at eteaff@mix.wvu.edu.

For information regarding your rights as a research subject, to discuss problems, concerns, or suggestions related to the research, to obtain information or offer input about the research, contact the Office of Research Integrity and Compliance at (304) 293-7073.

\section{Introduction}

You have been asked to participate in this research study, which has been explained to you by Dr. Daniels and Erin Teaff via email. This study is being conducted by Dr. Daniels and Erin Teaff in the Department of Counseling, Rehabilitation Counseling, and Counseling Psychology at West Virginia University.

\section{Purpose(s) of the Study}

The purpose of the study is to examine of the level of psychological trauma and resilience of victim and witness police officers who were involved in an ambush. You will be asked to respond to statements related to distress and resilience experienced as a result of an ambush. The researcher seeks to enroll approximately 128 police officers in this study.

\section{Who Can Be in This Study?}

1. Participants must be 18 years or older.

2. Participants must be a current or past sworn law enforcement officer. 
3. Participants must have been involved in an ambush and a sworn law enforcement office at the time of the ambush.

4. You must have been a victim or witness of the ambush. A victim officer is an officer who was injured as a result of the ambush. A witness officer is an officer who witnessed another officer being killed or injured, but were not injured themselves, during an ambush.

If you are under 18 years of age, have not been a sworn law enforcement officer, or have not been involved in an ambush while being a sworn law enforcement officer, you are not eligible for participation.

\section{Description of Procedures}

This study involves completing a voluntary and anonymous online survey. It will take approximately 10 minutes for you to complete. You will be asked to fill out a questionnaire regarding psychological trauma and resilience experienced after being involved in an ambush. You do not have to answer all the questions. Additionally, you have the right to terminate your participation at any time.

\section{Discomforts}

There are minimal risks from participating in this study. Participants may experience mild frustration associated with answering the questions. Additionally, participants might experience discomfort when answering questions related to a previous traumatic event. Some questions may trigger anxiety for participants. Participants that would like any mental health resources are encouraged to utilize the resources listed in the De-brief and Information for Participants section.

\section{Benefits}

You may not receive any direct benefit from this study. The knowledge gained from this study may eventually benefit others.

\section{Financial Considerations}

Participants will have to option to enter into a drawing for one of four \$25 Visa gift cards upon completion of the study. Participants will be asked to provide their name and email address if they are interested in being entered in to the gift card drawing. Information gathered for the drawing will not be linked to the individual survey responses, and only used for the drawing.

\section{Confidentiality}

Any information about you that is obtained as a result of your participation in this research will be kept as confidential as legally possible. Your research records and test results, just like hospital records, may be subpoenaed by court order or may be inspected by the study sponsor or federal regulatory authorities (including the FDA if applicable) without your additional consent. In addition, there are certain instances where the researcher is legally required to give information to the appropriate authorities. These would include mandatory reporting of infectious diseases, mandatory reporting of information about behavior that is imminently dangerous to your child or to others, such as suicide, child abuse, etc. In any publications that 
result from this research, neither your name nor any information from which you might be identified will be published without your consent.

\section{Voluntary Participation}

Participation in this study is voluntary. You are free to withdraw your consent to participate in this study at any time. In the event new information becomes available that may affect your willingness to participate in this study, this information will be given to you so that you can make an informed decision about whether or not to continue your participation. Refusal to participate or withdrawal will not affect you and will involve no penalty to you. Participants are encouraged to contact the researchers at the above listed email addresses or phone number if they have any questions.

\section{Please select one of the following options:}

O I have read the above information, I certify that I am at least 18 years old, a current or past sworn law enforcement officer who has been involved in an ambush, and agree to be in this study. Checking this box will take me to the survey.

o I do not want to be in this study. Checking this box will take me out of the survey. 


\section{APPENDIX H}

\section{FACEBOOK POST}

Are you a police officer who has been a victim or witness of an ambush? Researchers at West Virginia University are currently recruiting participants for a research study examining the psychological trauma and resilience of police officers involved in an ambush. In order to participate you must meet the following criteria:

- You must be 18 years of age or older

- You must be a current or past sworn law enforcement officers in the United States. Specifically, you will have been employed as a sworn law enforcement officer within a city, university or college, county, state, tribal, or federal agency during the time of the ambush

- You must have worn or carried a badge, carried a firearm, was duly sworn and had full arrest powers, was a member of a public governmental law enforcement agency and was paid from government funds set aside specifically for payment to sworn law enforcement, and was acting in an official capacity, whether on or off duty, at the time of the ambush.

- You must have been a victim or witness of the ambush. A victim officer is an officer who was injured as a result of the ambush. A witness officer is an officer who witnessed another officer being killed or injured, but were not injured themselves, during an ambush.

Participants will have the opportunity enter a raffle to win one of four $\$ 25$ Visa gift cards. The online survey will take approximately 10 minutes to complete and can be found at: [LINK TO SURVEY\}.

Please feel free to share this post. 


\section{APPENDIX I}

\section{PERMISSION TO USE IES-R}

From: Weiss, Daniel <Daniel.Weiss@ucsf.edu>

Date: Tue, Oct 10, 2017 at 1:09 AM

Subject: RE: Permission to use Impact of Event Scale - Revised

To: Erin Teaff <eteaff@mix.wvu.edu>

please see attached files

Daniel S. Weiss, Ph.D.

Editor Emeritus, Journal of Traumatic Stress

Professor of Medical Psychology

Department of Psychiatry

University of California San Francisco

San Francisco, CA 94143-0984

P: 4154767557

F: 4154767552

Mail Code: UCSF Box 0984-F

From: Erin Teaff [mailto:eteaff@ mix.wvu.edu]

Sent: Monday, October 9, 2017 1:27 PM

To: Weiss, Daniel <Daniel.Weiss@ucsf.edu>

Subject: Permission to use Impact of Event Scale - Revised

Dear Dr. Weiss:

I am a doctoral candidate from West Virginia University writing my dissertation titled Psychological Trauma and Resilience of Police Officers Involved in an Ambush, under the direction of my dissertation committee chaired by Dr. Jeffrey Daniels who can be reached at 304-293-

2235 or Jeffrey.Daniels@ mail.wvu.edu.

I would like your permission to use the Impact of Event Scale - Revised survey/questionnaire instrument in my research study. I would like to use and print your survey under the following conditions:

I will use the surveys only for my research study and will not sell or use it with any compensated or curriculum development activities.

- I will include the copyright statement on all copies of the instrument.

- I will send a copy of my completed research study to your attention upon completion of the study.

If these are acceptable terms and conditions, please indicate so by replying to me through email: eteaff@mix.wvu.edu

Sincerely,

Erin A. Teaff

$--$

Erin A. Teaff, M.S. CRC

Doctoral Candidate in Counseling Psychology

West Virginia University

502 Allen Hall

Eteaff@mix.wvu.edu 


\section{APPENDIX J}

\section{PERMISSION TO USE BRS}

From: Bruce Smith <bws0513@ gmail.com>

Date: Fri, Oct 20, 2017 at 2:10 PM

Subject: Re: Permission to use Brief Resilience Scale

To: Erin Teaff <eteaff@mix.wvu.edu>

Hi Erin,

I'm sorry that I couldn't respond sooner. Thanks for your interest in the Brief Resilience Scale. You are welcome to use it free of charge and for as much as you like. I have attached the original validation article, a copy of the scale as it usually appears in questionnaires, a chapter with suggested cut-offs for high and low resilience which also has data on predictors of resilience, an article with a validated Spanish version of the scale, and an article on the relationship between the BRS and various outcomes. Please let me know what you find when you can. I wish you the best in your research.

Kind Regards,

Bruce

On Mon, Oct 9, 2017 at 2:24 PM, Erin Teaff <eteaff@mix.wvu.edu> wrote:

Dear Dr. Smith:

I am a doctoral candidate from West Virginia University writing my dissertation titled Psychological Trauma and Resilience of Police Officers Involved in an Ambush, under the direction of my dissertation committee chaired by Dr. Jeffrey Daniels who can be reached at 304-293-

2235 or Jeffrey.Daniels@mail.wvu.edu.

I would like your permission to use the Brief Resilience Scale survey/questionnaire instrument in my research study. I would like to use and print your survey under the following conditions:

. I will use the surveys only for my research study and will not sell or use it with any compensated or curriculum development activities.

- I will include the copyright statement on all copies of the instrument.

- I will send a copy of my completed research study to your attention upon completion of the study.

If these are acceptable terms and conditions, please indicate so by replying to me through e-

mail: eteaff@mix.wvu.edu

Sincerely,

Erin A. Teaff

Erin A. Teaff, M.S. CRC

Doctoral Candidate in Counseling Psychology

West Virginia University

502 Allen Hall

Eteaff@mix.wvu.edu

$--$

Bruce W. Smith, Ph.D.

Department of Psychology

University of New Mexico

Albuquerque, NM 87131-1161

505-277-0643 


\begin{abstract}
APPENDIX K
Post-Study Debrief and Information for Participants

Again, thank you for your time. The specific purpose of the study was to examine of the level of psychological trauma and resilience of victim and witness law enforcement officers who were involved in an ambush.

Some of the questions asked in this study address distress during a potentially traumatic event and level of resilience. If now or in the future you or your family feel the need for help in dealing with stress, anxiety, or other psychologically related issues, there are a number of resources that can help deal with difficult topics, especially those that may be brought up during this study.

Contact Information:
\end{abstract}

In the event you experience any side effects or injury related to this research, you should contact Jeffrey Daniels, Ph.D. during business hours at (304) 293-2235 or Jeffrey.Daniels@mail.wvu.edu. If you have any questions, concerns, or complaints about this research, you can contact Dr. Daniels. Alternatively, you can contact Erin A. Teaff, M.S. at eteaff@mix.wvu.edu.

For information regarding your rights as a research subject, to discuss problems, concerns, or suggestions related to the research, to obtain information or offer input about the research, contact the Office of Research Integrity and Compliance at (304) 293-7073.

Below is a list of help services available:

\title{
Crisis Text Line
}

Text CONNECT to 741741

\section{Emergency Services}

911

First Responder Support Network

$1-415-721-9789$

www.frsn.org

International Critical Incident Stress Foundation, Inc.

1-410-313-2473 (Emergency Hotline)

www.icisf.org

National Suicide Prevention Lifeline

1-800-273-TALK (1-800-273-8255)

www.suicidepreventionlifeline.org 


\section{Safe Call Now}

$1-206-459-3020$

www.safecallnow.org

Substance Abuse and Mental Health Services Administration (SAMHSA) National Helpline 1-800-662-HELP (1-800-662-4357)

www.findtreatment.samhsa.gov 


\section{APPENDIX L}

\begin{tabular}{|c|c|c|}
\hline & & Question Text \\
\hline \multirow{24}{*}{ IES-R } & \multirow[t]{2}{*}{ Q1 } & Informed Consent \\
\hline & & \\
\hline & Q2 & Any reminder brought back feelings about it. \\
\hline & \multirow{2}{*}{ 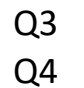 } & I had trouble staying asleep. \\
\hline & & Other things kept making me think about it. \\
\hline & Q5 & I felt irritable and angry. \\
\hline & \multirow{2}{*}{$\begin{array}{l}\text { Q6 } \\
\text { Q7 }\end{array}$} & I avoided letting myself get upset when I thought about it or was reminded of it. \\
\hline & & I thought about it when I didn't mean to. \\
\hline & \multirow{2}{*}{$\begin{array}{l}\text { Q8 } \\
\text { Q9 }\end{array}$} & I felt as if it hadn't happened or wasn't real. \\
\hline & & I stayed away from reminders of it. \\
\hline & Q10 & Pictures about it popped into my mind. \\
\hline & \multirow{2}{*}{ Q11 } & I was jumpy and easily startled. \\
\hline & & I tried not to think about it. \\
\hline & Q13 & I was aware that I still had a lot of feelings about it, but I didn't want to deal with them. \\
\hline & Q14 & My feelings about it were kind of numb. \\
\hline & \multirow{2}{*}{$\begin{array}{l}\text { Q15 } \\
\text { Q16 }\end{array}$} & I found myself acting or feeling like I was back at that time. \\
\hline & & I had trouble falling asleep. \\
\hline & \multirow{2}{*}{ Q17 } & I had waves of strong feelings about it. \\
\hline & & I tried to remove it from my memory. \\
\hline & Q19 & I had trouble concentrating. \\
\hline & \multirow{2}{*}{$\begin{array}{l}\text { Q20 } \\
\text { Q21 }\end{array}$} & $\begin{array}{l}\text { Reminders of it caused me to have physical reactions, such as sweating, trouble } \\
\text { breathing, nausea, or a pounding heart. }\end{array}$ \\
\hline & & I had dreams about it. \\
\hline & Q22 & I felt watchful and on-guard. \\
\hline & \multirow[t]{2}{*}{ Q23 } & I tried not to talk about it. \\
\hline \multirow[t]{7}{*}{ BRS } & & \\
\hline & \multirow{2}{*}{ Q24 } & I tend to bounce back quickly after hard times. \\
\hline & & I have a hard time making it through stressful events. \\
\hline & $\begin{array}{l}\text { Q25 } \\
\text { Q26 }\end{array}$ & It does not take me long to recover from a stressful event. \\
\hline & Q27 & It is hard for me to snap back when something bad happens. \\
\hline & Q28 & I usually come through difficult times with little trouble. \\
\hline & \multirow[t]{2}{*}{ Q29 } & I tend to take a long time to get over set-backs in my life. \\
\hline \multirow[t]{7}{*}{ Demographics } & & \\
\hline & Q30 & Gender: \\
\hline & \multirow{2}{*}{ Q31 } & Age at Time of Ambush: \\
\hline & & What is your race/ethnicity? \\
\hline & Q33 & Level of Education: \\
\hline & \multirow{2}{*}{ Q34 } & Work Status: \\
\hline & & Type of agency: \\
\hline
\end{tabular}


Q36 Rank in Agency:

Q37 Year of Police Experience at Time of Ambush:

Q38 Date of Ambush:

Q39 Type of Assignment:

Q40 Involvement in Ambush:

Q41 Status of Victim Officer:

Q42 Type of Weapon Used by Offender:

Q43 Did you receive counseling after the ambush? 